\title{
SOCIALISMO HAYEKIANO*
}

\section{Fernando Atria}

Este artículo discute dos ideas desarrolladas por Hayek en su trilogía Law, Legislation and Liberty. La primera es la distinción entre órdenes de dos tipos, cuyos nombres más famosos son "espontáneos" y "creados". La segunda es que la idea misma de "justicia social" es, en el contexto de órdenes espontáneos, un sinsentido, un "espejismo". Esto es porque "justo" e "injusto" son predicados de las consecuencias de las acciones humanas, mientras los resultados de los órdenes espontáneos no son consecuencia de la acción de nadie en el sentido relevante.

Contra Hayek, este artículo alega que la primera idea es verdadera e importante pero la segunda fundamentalmente equivocada, porque no entiende la noción de orden espontáneo. A partir de un análisis cuidadoso del intento (y fracaso) de Hayek de identificar lo característico de los órdenes espontáneos, este artículo defiende una explicación de la "espontaneidad" de los órdenes espontáneos y su conexión interna con la

Fernando Atria. Profesor de Derecho, Universidad de Chile y Universidad Adolfo Ibáñez.

* La versión original de este texto fue preparada para ser presentada a las III Jornadas de Filosofía Política, organizadas por los estudiantes de derecho de la Universidad de Chile en agosto de 2008. Agradezco a los organizadores su invitación a esas jornadas. Agradezco también al Fondo Nacional para la Investigación Científica y Tecnológica, de cuyo proyecto 1060255 este artículo es parte. El artículo se ha beneficiado de las observaciones de dos lectores anónimos de Estudios Públicos. 
libertad que muestra que las dos ideas iniciales no tienen entre sí conexión alguna. De este modo, el argumento pretende rescatar la idea de orden espontáneo del pensamiento neoliberal y ponerlo al servicio de una teoría política que, en el sentido explicado, puede correctamente ser descrita como "socialismo". De ahí "socialismo hayekiano".

Habiendo hecho eso, el artículo termina analizando el caso del sistema educacional chileno para mostrar el modo en que mediante órdenes espontáneos es posible producir reconocimiento recíproco y unificación de intereses, ideas claves (según se explica) para entender una forma de socialismo que sea capaz de dar cuenta de la experiencia de los "socialismos reales".

Palabras clave: socialismo; justicia social; órdenes espontáneos (Hayek); libertad e igualdad.

Recibido: octubre 2009. Aceptado: octubre 2010.

Tengo una observación que hacer a esta frase de su carta: el momento de la acción. Quizás usted todavía mantiene la opinión de que no hay reforma posible ahora sin un coup de main, sin lo que antes se denominaba revolución y que no es en realidad sino un shock. Esa opinión, que entiendo, que excuso, y que estoy plenamente dispuesto a discutir, porque la sostuve por mucho tiempo, es una que mis estudios más recientes me han llevado a abandonar por completo. Creo que ella no es necesaria para nuestro éxito; y que en consecuencia no debemos abogar por la acción revolucionaria como un medio de reforma social, porque ese pretendido medio sería simplemente una apelación a la fuerza, a la arbitrariedad; en breve, una contradicción. Yo

por mi parte pondría el problema de este modo: devolver a la sociedad, a través de una combinación económica, la riqueza de la que se le ha privado a través de otra combinación económica. Dicho de otro modo: volver, a través de la economía política, la teoría de la propiedad contra la propiedad, de modo de engendrar lo que ustedes los socialistas alemanes llaman comunidad y que yo me limitaría por el momento a llamar libertad o igualdad. Creo conocer el medio para solucionar este problema sólo con un corto retraso; yo preferiría entonces quemar a la propiedad en el fuego lento, antes que darle nuevos bríos por hacer una noche de San Bartolomé de los propietarios.

P. J. Proudhon,

Carta a K Marx, 17 de mayo de 1846. 


\section{INTRODUCCIÓN: NUESTRA SITUACIÓN HISTÓRICO-ESPIRITUAL}

$\mathrm{E}$ desarrolla dos ideas que quiero discutir en este artículo. Hayek alega que ellas están vinculadas recíprocamente, y esta putativa vinculación recíproca caracteriza, a mi juicio, nuestra situación histórico-espiritual. La tesis hayekiana de la implicación recíproca entre estas dos ideas es, sin embargo, falsa, y por eso es posible rescatar la primera y desechar la segunda.

La primera idea es que hay una distinción entre dos tipos de órdenes. Hayek los denomina de diversas maneras: a veces órdenes espontáneos y órdenes creados, a veces sistemas de mandatos y sistemas de reglas de conducta justa, a veces cosmos y taxis, etc. Aunque la caracterización de cada uno es mucho menos obvia de lo que parece, por ahora podemos usar el primer par de etiquetas para identificarlos. Un orden espontáneo es un orden que (como el mercado) no requiere para su existencia de un creador que haya decidido cómo han de ordenarse sus diversas partes. Al contrario, él es emergente respecto de las acciones descentralizadamente realizadas por cada elemento del orden. Que el orden sea emergente significa aquí que es la consecuencia no querida por nadie (o al menos no necesariamente querida) de la forma en que interactúan entre sí los diversos elementos. Un orden creado es, a la inversa, uno que supone un creador que, mediante mandatos, asigna a cada elemento una función determinada. Hayek cree que esta distinción es políticamente central, porque los órdenes espontáneos preservan la libertad mientras los órdenes creados la amenazan, por lo que quienes creen en la idea de una sociedad libre tienen una razón para preferir los órdenes espontáneos ${ }^{1}$.

La segunda idea es que la justicia social es un "espejismo", al menos cuando ella es predicada de los resultados de los órdenes espon-

${ }^{1}$ Esta frase debe ser, desde luego, calificada: Hayek no necesita suponer que en una sociedad libre sólo hay órdenes espontáneos. Es anticipable que en numerosas aunque restringidas condiciones será necesario introducir órdenes creados. La frase del texto debe ser entendida como aludiendo a la forma de los órdenes fundamentales en el contexto de los cuales transcurre la vida de los individuos. La posibilidad de que incluso una "gran sociedad" utilizara órdenes creados en contextos especificados es concedida por Hayek: es posible, dice Hayek aprobatoriamente, "suplementar sus resultados [de los órdenes espontáneos] mediante los esfuerzos de varias organizaciones" (Hayek, Rules and Order, 51). 
táneos. En efecto, ellos no pueden ser calificados de justos o injustos, porque no son el resultado de la acción de nadie en particular: no se han producido como consecuencia de la acción intencional de nadie. A pesar de que los resultados de los órdenes espontáneos pueden parecer justos o injustos cuando son juzgados por referencia a un estándar externo a ellos, no son el tipo de cosas del que puede predicarse justicia o injusticia, precisamente porque son consecuencias de las acciones de agentes que no buscan producir esos resultados, sino sus propios fines. Hablar de la "justicia" o "injusticia" de los resultados de un orden espontáneo no sería sino una forma "primitiva", "inmadura" e "ingenua"² de hablar, una que asume que esas consecuencias son el resultado de la acción de alguien (una personificación animista del mercado, por ejemplo). Calificar esos resultados como "justos" o "injustos" tiene tanto sentido político como calificar de injusto el hecho de que alguien nazca ciego, o que un terremoto asuele una región y no otra.

¿Por qué volver a estas ideas? Uno podría decir que la filosofía política neoliberal tuvo su momento de gloria en los años 70 (con la publicación en 1973 de Rules and Order, el primer volumen de Law, Legislation and Liberty y en 1974 de Anarchy, State and Utopia de Nozick), anticipando su momento de gloria en las prácticas políticas occidentales (Pinochet y los Chicago-boys desde mediados de los ' 70 , Thatcher desde 1979, Reagan desde 1982), pero que afortunadamente nos hemos librado de ella. Aunque (en una suerte de 'damage-limitation exercise') Hayek intenta hacer suyo el argumento de Rawls en Teoría de la Justicia $(1970)^{3}$, podría decirse que después de ese libro insistir en que el concepto de justicia "social" carece de contenido puede parecer absurdo. La idea defendida por Hayek, o la idea de Nozick de que sólo el Estado mínimo se justifica, pareciera ser en algún sentido una idea superada por la historia.

Y sin embargo no es así. Vivimos bajo la hegemonía neoliberal. Una teoría es en este sentido "hegemónica" cuando informa nuestras formas políticas de vida, de modo tal que, aun cuando en sus formula-

\footnotetext{
2 Ibid., Rules and Order, 62-63.

${ }^{3}$ En el segundo volumen de la trilogía Hayek afirma que "las diferencias entre nosotros [Hayek y Rawls en Teoría de la Justicia] parecen más verbales que substanciales" (ibid., xiii), una afirmación que (me imagino) sería enfáticamente negada por todo rawlsiano (aunque, como se explica en el texto más abajo, es en un sentido relevante correcta).
} 
ciones "académicas" esté desacreditada o haya incluso sido refutada, ella constituye, políticamente hablando, el "sentido común", el contexto en el cual intuitivamente y por defecto las cuestiones son discutidas o decididas 4 .

¿No es, sin embargo, implausible dar por "hegemónica" una ideología en su versión más extrema, la de Hayek (o, en su versión filosóficamente sofisticada, de Nozick)? La respuesta es que la teoría ya no se nos aparece como extrema, precisamente porque informa de modo intuitivo nuestro sentido común. Ya no nos parece "extremo", sino "realista", sostener que la igualdad como ideal político (es decir, la igual libertad) es, como dice Hayek, un "espejismo". En estas circunstancias, para reducir la disonancia cognitiva (es decir, la distancia entre el mundo como creemos que es y el mundo como nos gustaría que fuera) nos convencemos (primero) de que las uvas estaban verdes, es decir, que la idea misma de que era posible que nuestras prácticas políticas encarnaran la trilogía revolucionaria de libertad, igualdad y fraternidad fue una insensatez, y (segundo) de que, por consiguiente, el hecho de que hoy nuestra acción política no tenga ese norte no quiere decir que nos hemos hecho conformistas sino que ahora entendemos mejor nuestra condición y sobre todo nuestras limitaciones. Nuestras formas políticas de vida, entonces, son ahora más maduras, y no más de derecha.

De modo que para que la idea neoliberal pudiera pasar a formar parte del sentido común era necesario que dejara de ser identificada como "neoliberal", y fuera presentada en un envoltorio políticamente más atractivo. Ésta es la función que, en la academia, cumplieron obras como el aludido libro de Rawls, que sin decirlo declaró a la igualdad políticamente irrelevante. En efecto, ésa es la función del principio distributivo rawlsiano, llamado "principio de la diferencia" (que las desigualdades sólo se justifican si ellas benefician a los que quedan peor situados $^{5}$ ). Porque para el principio de la diferencia lo que es problemático no es la desigualdad, sino la pobreza (aunque ésta se mida relati-

${ }^{4}$ Como lo dice MacIntyre del emotivismo: toda filosofía moral implica una sociología, y lo que le da relevancia política no es su éxito académico sino el hecho de que la sociología correspondiente sea dominante. El punto de MacIntyre es que a pesar de que el emotivismo como fue formulado y defendido por autores como Charles Stevenson y otros es hoy sólo una pieza de museo, la nuestra es una época emotivista porque el emotivismo se ha encarnado en nuestras formas de vida. Sobre este punto véase MacIntyre, After Virtue, 23.

${ }^{5}$ Rawls, Theory of Justice, $§ 11$. 
vamente). De acuerdo al principio de la diferencia, la justicia no exige, ni siquiera como un ideal, la reducción de la desigualdad, sino sólo la de las desigualdades que no mejoran a los que quedan peor situados (aunque los mejoren mucho menos de lo que benefician a los mejor situados $)^{6}$.

Institucionalmente hablando, la idea detrás del principio de la diferencia de Rawls se manifiesta en lo que puede llamarse el "principio de focalización": la tesis de que las prestaciones denominadas "sociales" del Estado deben alcanzar solamente a los más necesitados, ignorando a quienes pueden obtener esas prestaciones en el mercado. Este principio, introducido en Chile por los "Chicago-boys", hoy parece de toda evidencia, y desde luego tiene alguna racionalidad. Pero nótese que si éste es el principio que estructura el gasto social no puede decirse que la finalidad del mismo sea la igualdad, sino acabar con la pobreza ${ }^{7}$. T. H. Marshall, en su famoso texto sobre los derechos sociales, que proveyó del fundamento teórico del naciente Estado de bienestar británico, decía que lo característico de los derechos sociales era su pretensión de acabar con las diferencias de clase

La reducción de las desigualdades de clase es también la finalidad de los derechos sociales, pero ha adquirido un nuevo sentido. Ya no es solamente un intento de disminuir los desagrados obvios de la miseria. Ahora se presenta como acción tendiente a modificar todo el patrón de desigualdad social. Ya no se satisface con levantar el nivel del suelo en el subterráneo del edificio, dejando los pisos superiores como estaban. Ha comenzado a remodelar el edificio completo, y puede incluso convertir un rascacielos en un bungalow ${ }^{8}$.

El neoliberal respondería que la finalidad de los "derechos sociales" (es decir, la finalidad de los programas públicos de bienestar) es precisamente "levantar el nivel del suelo en el subterráneo del edificio", y por eso de lo que se trata es de focalizar el gasto social solamente a quienes están ahí: subterra. Pero hoy esta idea no es entendida como neoliberal. Es una de las ideas sobre las cuales en Chile hay consenso

\footnotetext{
${ }^{6}$ Véase Atria y Michelon, "Una Crítica al Principio de la Diferencia".

${ }^{7}$ Sobre la diferencia entre pobreza y desigualdad, y sobre el modo en que ella se correlaciona con dos comprensiones de los derechos sociales, y con la exigencia de "focalización" del gasto social, véase Atria, Mercado y Ciudadanía en la Educación, 68-74.

${ }^{8}$ Marshall, Citizenship and Social Class, 8-17 [22-36].
} 
político. En otras palabras, la demanda de igualdad ha desaparecido de nuestro paisaje político. De hecho, incluso en el lenguaje ella ha sido desplazada: hoy ya no se habla de "igualdad" sino de "equidad", y todos sabemos que la equidad es igualdad en la aplicación de una regla que no se tematiza. La equidad, entonces, no provee de un punto de vista desde el cual juzgar nuestras prácticas políticas. Y para compensar la pérdida producida por el abandono de la idea de igualdad, la izquierda ha abrazado

\begin{abstract}
un pensamiento posmodernista, antiempirista e intelectualmente oscuro. Este pensamiento parece incapaz de imaginar que una política pueda reposar en una combinación de visiones ideológicas de lo que es normativamente bueno y de estudios empíricos sobre lo que es posible en el plano práctico. Del mismo modo, la izquierda en gran parte ha abandonado la idea de una política fundada en los derechos humanos universales y ha sido sobrepasada por lo que llaman la política identitaria. En lugar de impulsar una política para todos, la izquierda se ha convertido en un conglomerado de fuerzas que se esmera en poner por delante los intereses de diversos grupos cuyos miembros se consideran oprimidos debido a su identidad común y marginalizada, trátese de raza, de religión, de orientación sexual, de especificidad de sexos, de intereses culturales, de handicaps físicos y mentales, etc. ${ }^{9}$.
\end{abstract}

En este artículo pretendo explicar el modo en que es hoy posible, a mi juicio, articular una visión de lo que es "normativamente bueno" sin que sea ingenua, y de lo que es empíricamente posible sin que sea cínica. La pretensión, desde luego, no es sino mostrar la forma general de una visión de este tipo. En este sentido este artículo es programático: apunta a una tarea por realizar, no reporta resultados ya alcanzados.

\title{
"Socialismo"
}

Para comenzar necesitamos una idea, al menos preliminar, de qué significa la expresión "socialismo". La cuestión es importante porque las ideas políticas se estructuran, por así decirlo, jerárquicamente. Tradicionalmente, "socialismo" se ha identificado con una determinada

\footnotetext{
${ }^{9}$ Rothstein, "El Fracaso de los Socialistas Europeos".
} 
forma institucional de socialismo, que es la propiedad pública de los medios de producción. Pero las soluciones institucionales suponen problemas pre-institucionales, por lo que una idea como "socialismo" no puede ser definida por referencia sólo a una fórmula institucional. Las instituciones no son capaces de dar cuenta de su propio sentido, y deben entonces buscarlo en ideas substantivas que ellas suponen. Así, por ejemplo, el valor político de la democracia no puede estar en el gobierno de la mayoría, porque el gobierno de la mayoría es el mecanismo institucional para asegurar o garantizar o realizar algo. El valor de la democracia debe estar en ese "algo". Por supuesto, eso no quiere decir que entre la idea de democracia y la de gobierno de la mayoría no hay conexión alguna; lo probable es lo contrario: que la identificación de una determinada idea con una institución dé cuenta del hecho de que esa institución es la manera de hacer probable esa idea. Si esta conexión es suficientemente estrecha, es perfectamente razonable usar la denominación de la idea para denominar la institución que la hace probable.

Pero aun en ese caso es importante mantener la distinción entre la idea y la institución que la hace probable, porque es perfectamente posible que la institución desarrolle patologías que conspiran en contra de la idea (la democracia degenerando en "tiranía de la mayoría", o el socialismo degenerando en "totalitarismo"). Cuando eso es el caso, uno no puede apresurarse a declarar la idea muerta porque su correlato institucional ha fallado. Si la idea retiene sentido e importancia política, ése es en realidad el momento para la imaginación institucional: para volver a pensar sobre el sentido de la idea y su relación con instituciones que la hagan probable. En este esfuerzo de imaginación institucional tener una conciencia clara de las razones que llevaron a las instituciones anteriores a traicionar la idea respectiva es usualmente el punto de partida. El de llegada, en la medida en que el esfuerzo es exitoso, es una nueva forma institucional.

Por las razones anteriores, este artículo procede asumiendo que la idea socialista que la forma institucional de la propiedad estatal de los medios de producción intentaba hacer probable es una idea que retiene todo su valor político; pero que es necesario asumir el hecho de que formas institucionales originalmente pensadas para hacer probable una vida humana emancipada terminaron ahogando la libertad. En esas circunstancias deberemos volver sobre la idea, y preguntarnos dónde yace su valor político; luego tendremos que indagar sobre las formas 
que pueden hacerla probable una vez que asumimos que los llamados "socialismos reales" produjeron lo contrario de lo que se esperaba de ellos.

Porque no descansa en una forma institucional, sino en una idea substantiva, la opción de definir el socialismo por su compromiso con la igualdad es más prometedora. "Socialismo" sería, en esta comprensión, una determinada comprensión de la igualdad, como la que Gerald Cohen llama "igualdad socialista de oportunidades"10; pero a mi juicio esta explicación también se queda corta. La razón es que la idea de igualdad, por sí sola, no puede designar un valor político en sus propios términos. La igualdad es un régimen de distribución de algo, y lo importante debe estar en ese algo. Esto puede apreciarse diciendo que carece de sentido decir de X que es igual.

Por eso es interesante notar que Proudhon, en la carta a Marx que sirve de epígrafe de este artículo, equipara igualdad a libertad. En esta comprensión, el "algo" de cuyo régimen se trata es la libertad. El socialismo sería una idea fundada en la libertad, y la igualdad fijaría el régimen de esa libertad: se trata de libertad igual (como el mismo Cohen ha mostrado, la falta de dinero es una forma de falta de libertad ${ }^{11}$ ).

Pero esta explicación queda todavía expuesta a la pregunta: ¿por qué es importante que la libertad sea igual? ¿En qué sentido la libertad de $\mathrm{X}$ se ve afectada por el hecho de que Y tiene más libertad? Por esto el argumento igualitarista siempre está expuesto a la objeción de la "nivelación hacia abajo"12. Mi impresión es que esta objeción alcanza a cualquier comprensión del socialismo que lo entiende como fundado en una idea de igualdad al modo ya indicado: como igualdad de algo. Siempre la pregunta será: ¿si de lo que se trata es de maximizar el goce de ese algo, en qué sentido afecta a uno el que otro tenga más? Eso sugiere cambiar la estrategia, y entender que la igualdad (o mejor dicho, la igual libertad) no es el valor fundamental que define al socialismo. Recorriendo en sentido inverso el camino seguido por Proudhon en la carta ya mencionada, tendríamos que decir que el socialismo se define por una determinada comprensión de la comunidad, es decir, por una determinada comprensión de la forma en que los seres humanos han

${ }^{10}$ Cohen, "Por qué No el Socialismo", 68-69.

${ }^{11}$ Cohen, "Libertad y Dinero".

12 Sobre la nivelación hacia abajo, véase Atria, Mercado y Ciudadanía en la Educación, 85-88. 
de vivir juntos si sus vidas han de desarrollarse en plenitud. La idea ha sido expresada (tanto en sus términos como en contraposición con el liberalismo) por Terry Eagleton:

El socialismo es la respuesta a la pregunta de qué ocurre cuando [...] universalizamos la idea de auto-realización, vinculándola a la $[\ldots]$ creencia de que debe ser para todos. Si esto es así [...], podemos intentar organizar la vida política de modo que cada uno realice sus capacidades únicas sin interferir con los otros (una doctrina conocida como liberalismo), o podemos organizar nuestras instituciones políticas de modo que su realización sea recíproca, una teoría conocida como socialismo ${ }^{13}$.

El socialismo es entonces la consecuencia política de una determinada comprensión de la naturaleza humana o, en otros términos, de la realización humana, es decir, de la manera en que ha de ser vivida una vida plenamente humana ${ }^{14}$. La diferencia entre liberalismo y socialismo es una diferencia entre dos concepciones de qué es lo que constituye una vida realizada. Mientras el liberalismo insiste en que la realización es individual, y por consiguiente que la contribución que cada uno ha de hacer a la realización de los demás se limita a no interferir con ellos de modos ilícitos, el socialismo insiste en la dimensión recíproca de la realización. El liberalismo entiende que el paradigma de relación humana es la interacción de mercado, en la que cada una de las partes intenta lograr (lo que necesita para) sus fines en la mayor medida posible dando tan poco como sea estrictamente necesario al otro, mientras que el socialismo entiende que el paradigma de relación humana es la amistad, en la que lo que mueve a cada amigo es el bienestar del otro.

Puesto en estos términos, no parece haber razón alguna para preferir al liberalismo sobre el socialismo. Dicho de otro modo, la visión de la realización humana que el liberalismo supone es groseramente implausible. "Fue muy rico, y cada vez que tuvo que negociar con otro salió ganando a expensas de su contraparte" no es la descripción de una vida realizada que uno esperaría escuchar de alguien en un obituario. Los mismos autores neoliberales esperarían que en sus obituarios se destacara el modo en que contribuyeron a la realización de otros (aunque no sea por advertirnos de lo seductor que es el camino de ser-

\footnotetext{
${ }^{13}$ Eagleton, After Theory, 122.

${ }^{14}$ Véase, adicionalmente a lo explicado más abajo, Atria, "La Verdad y lo Político (i)" y "La Verdad y lo Político (ii)".
} 
vidumbre, etc.). Esto podría expresarse diciendo que, normativamente, el socialismo es indiscutiblemente superior al liberalismo. Pero ahora estamos considerando socialismo y liberalismo no como filosofías morales, sino como teorías políticas. La pregunta política no es cómo viviríamos si el mundo fuera perfecto, sino cómo vivir en el mundo como es. Y claro, éste siempre ha sido el punto fuerte del liberalismo: que la pretensión socialista de que podríamos vivir vidas plenamente realizadas en el sentido indicado más arriba, en las condiciones reales de vida que enfrentamos, lleva al totalitarismo. Y, si hemos de ser honestos, el hecho de que la expresión "socialismos reales" designe hoy distopías totalitarias hace que la objeción liberal sea hoy más fuerte que antes.

El liberal cree que el socialismo, la idea de que podremos relacionarnos en la lógica de la amistad fuera de ámbitos restringidos de relaciones personales (como la familia) es incompatible con la naturaleza humana, por lo que el socialista necesita, para avanzar su programa, hacerle violencia. En este sentido, el más fundamental, la gramática profunda del liberalismo es hobbesiana ${ }^{15}$. El socialista cree, por otra parte, que la existencia precede la conciencia, y que entonces eso que Hobbes considera "natural" no es sino la consecuencia de una forma determinada de socialización: el hombre no es naturalmente el lobo del hombre; el hombre aprende a comportarse como el lobo del hombre viviendo bajo condiciones en las que el que actúa de ese modo triunfa y el que actúa con amor hacia la humanidad recibe lo que en términos de teoría de juegos suele denominarse "el pago del sucker".

El atractivo obvio de la concepción socialista de la realización humana no es suficiente para negar que en estas condiciones el liberalismo lleva las de ganar. Porque si el liberal tiene razón, y el sujeto hobbesiano es "natural", entonces la idea socialista es imposible (ésta es la razón por la que el neoliberalismo celebra tan estentóreamente la biología neo-darwinista); pero si es socialmente construido, la objeción

${ }^{15} \mathrm{Y}$ al socialista el liberal respondería ad hominem, como Hobbes en el Leviathan: "Haced, pues, que se considere a sí mismo; cuando emprende una jornada, se procura armas y trata de ir bien acompañado; cuando va a dormir cierra las puertas; cuando se halla en su propia casa, echa la llave a sus arcas; y todo esto aun sabiendo que existen jueces y funcionarios públicos armados para vengar todos los daños que le hagan. ¿Qué opinión tiene así, de sus conciudadanos, cuando cabalga armado; de sus vecinos, cuando cierra sus puertas; de sus hijos y sirvientes, cuando cierra sus arcas? ¿No significa esto acusar a la humanidad con sus actos, como yo lo hago con mis palabras?" (Hobbes, Leviathan, 103). 
neoliberal asume una forma distinta, menos decisiva filosóficamente pero al menos tan efectiva en términos políticos: para contrarrestar la corrupción que el capitalismo produce en la subjetividad humana, que ha transformado seres cuyo fin es la amistad en seres hobbesianos, parecería necesario ignorar las finalidades, deseos e intereses de los sujetos concretos, y tratarlos no conforme a lo que ellos creen que quieren (porque están corrompidos), sino a lo que corresponde a su "verdadera" naturaleza, a lo que ellos "verdaderamente" quieren. Los "socialismos reales" son la consecuencia política de esta irrelevancia de los intereses y deseos concretos de individuos realmente existentes. En la forma especialmente influyente que Isaiah Berlin dio a esta idea,

Una cosa es decir que yo sé lo que es bueno para $\mathrm{X}$, mientras que él mismo no lo sabe, e incluso ignorar sus deseos por el bien mismo y por su bien, y otra cosa muy diferente es decir que eo ipso lo ha elegido, desde luego no conscientemente, no como él aparece en la vida ordinaria, sino en su rol de yo racional, uno que puede ser desconocido para su yo empírico, el yo 'verdadero', que discierne lo bueno y no puede evitar elegirlo una vez que se ha revelado. Esta monstruosa personificación que consiste en equiparar lo que $\mathrm{X}$ decidiría si fuese algo que no es, o por lo menos no es aún, con lo que realmente quiere y decide, está en el centro mismo de todas las teorías políticas de la autorrealización ${ }^{16}$.

La trampa, por supuesto, está en la última frase, que no es sino una grosera exageración. No parece razonable entender que en el centro mismo de todas las teorías de la autorrealización esté la cuestión de qué respeto merecen los deseos e intereses de seres que no han podido realizarse porque no han vivido de acuerdo a su propia naturaleza. $\mathrm{Si}$ el desprecio al yo "empírico" estuviera en el centro mismo de toda teoría de la autorrealización, entonces el socialismo (que es desde luego una teoría política de la autorrealización) implicaría necesariamente el desprecio por ese yo. Aquí se hace relevante la construcción jerárquica de las teorías políticas. Lo que está "en el centro mismo" de una teoría de la autorrealización es la cuestión de qué es la autorrealización. La pregunta sobre cómo ha de ser enfrentado el hecho de que hoy tenemos, dadas las condiciones en las que vivimos, una comprensión deformada de nuestra propia realización, no está en el centro de la teoría, porque

${ }^{16}$ Berlin, "Dos Conceptos de Libertad". 
de hecho su respuesta depende de lo que sí está en el centro, la idea de realización (y en particular la relación que hay entre la realización y la manera en que llegamos a vivir en condiciones de vida realizadas).

Lo que más arriba fue denominado "nuestra situación históricoespiritual" se caracteriza por aceptar algo como la exageración de Berlin. Y este artículo tiene la pretensión de ofrecer una salida. No una completamente depurada y elaborada, porque como está dicho este artículo tiene una orientación programática. Lo que pretende es sugerir una manera de pensar en el socialismo como teoría política de la realización recíproca de un modo que esté radicalmente libre del riesgo que identificó Berlin.

Y para eso puede ser útil volver a esa exageración. Ya hemos visto que en el centro de una teoría política de la autorrealización no puede estar la idea de que nuestros "yos" empíricos deben ser ignorados o despreciados. Como está dicho más arriba, ahí lo que ha de estar es una idea acerca de en qué consiste la realización humana. En un lugar cercano al centro (aunque no en el centro) está la idea de que lo que en las condiciones en las que vivimos se nos aparece como realización puede perfectamente no ser sino un engaño (=alienación). Y sólo entonces se plantea la pregunta de qué respeto merece el yo empírico cuando es un yo alienado cuyos deseos o intereses dan cuenta de la corrupción de sus formas de vida.

La respuesta que Berlin cree que es implicada por "toda" teoría política de la autorrealización entiende la realización conforme a lo que podríamos llamar el "principio portaliano". Como se sabe, Portales creía que los ciudadanos chilenos estaban "llenos de vicios y [carecían] de toda virtud", lo que a su juicio implicaba la necesidad de "un Gobierno fuerte, centralizador", de modo que "cuando se hayan moralizado, venga el Gobierno completamente liberal, libre y lleno de ideales, donde tengan parte todos los ciudadanos"17. Lo que caracteriza al principio portaliano es que entiende que lo que se logrará en el futuro es externo al sujeto en cuestión, por lo que puede caerle desde fuera: así, el desarrollo de las virtudes necesarias para la democracia es posible excluyendo a los ciudadanos "realmente existentes" de la política; y el desarrollo de las condiciones necesarias para la autorrealización de cada uno es posible a través de un ejercicio del poder que desprecia los intereses y deseos de los individuos realmente existentes.

${ }^{17}$ Carta de Portales a Cea, escrita en Lima en marzo de 1822, y disponible en múltiples fuentes. Véase, por ejemplo, Silva, Ideas y confesiones de Portales, 15. 
Es este principio portaliano el que constituye el blanco legítimo de la crítica de Berlin, y no "toda" teoría política de la autorrealización. Es este principio portaliano el que explica por qué la apelación a la acción revolucionaria, como decía Proudhon (véase el epígrafe de este artículo), termina siendo "una apelación a la fuerza, a la arbitrariedad; en breve, una contradicción”. El problema del socialismo no es un problema de visión (en el sentido de que el punto de llegada sea problemático o no sea atractivo) es un problema de transición. El problema no es que no sepamos dónde queremos llegar, sino cómo movernos hacia allá. Lo que necesitamos, en otras palabras, es una brújula socialista ${ }^{18}$ : algo que nos permita saber qué cuenta como un movimiento en la dirección correcta, de modo de orientarnos incluso cuando el punto de llegada siga estando más allá del horizonte.

Un socialismo que rechaza el principio portaliano insiste en que efectivamente la forma en que nos concebimos a nosotros bajo el capitalismo es una forma distorsionada. Pero la fuerza de esa forma radica en que nos ofrece una representación distorsionada, no enteramente falsa. De lo que se trata es de corregir la distorsión. La distorsión es en la manera en que bajo el mercado aprendemos a encontrarnos con el otro. Lo que caracteriza al mercado es que en él las partes no pueden sino ver sus intereses como contrapuestos. Lo que uno gana lo pierde el otro. Sin perjuicio de que desde el punto de vista social el intercambio no sea un juego de suma cero, desde el punto de vista de las partes lo es. El mercado niega precisamente la idea socialista de la realización recíproca, porque nos exige entender al otro con una mezcla de codicia (porque son oportunidades de enriquecimiento) y temor (porque son una amenaza $)^{19}$. El socialista cree que entender que la realización es recíproca es necesario para que todos vivamos vidas más plenas, por lo que si a los individuos la realización se aparece como algo individual eso tiene que ser porque las condiciones en las cuales deben actuar distorsionan la realidad, mostrándoles las cosas como no son. Si en el mercado cada uno debe ver a los demás con codicia y temor eso es reflejo no de una inexistente naturaleza humana hobbesiana, sino del modo en que el mercado necesita que los individuos se relacionan entre sí. Alternative".

${ }^{18}$ La expresión es de Erik Olin Wright, "Compass Points: Towards a Socialist ${ }^{19}$ Cohen, "Por Qué No el Socialismo", 105. 
Es aquí donde es relevante volver sobre la noción hayekiana de orden espontáneo. En un sentido que será defendido más abajo, la razón por la que la idea de los órdenes espontáneos es políticamente relevante es que ellos son espacios en los que los individuos pueden perseguir sus fines, sin tener que abandonarlos o fingir que los abandonan para poder actuar con éxito. Con demasiada frecuencia sin embargo (y desde luego, por Hayek mismo) se ha creído que un contexto en el cual cada individuo persigue sus fines es uno en el que la interacción de esos individuos deberá ser comprendida, por los mismos agentes, como una en la que sus intereses están en conflicto. Si esto fuera así, habría una contradicción directa e inevitable entre la idea misma de órdenes espontáneos y socialismo. Pero un análisis cuidadoso de la idea hayekiana muestra que no hay razón a priori para entender que hay una necesidad interna de que los individuos que actúan bajo órdenes espontáneos necesiten, para ser exitosos, mirar sus intereses como opuestos. Quizás es posible utilizar órdenes espontáneos para hacer más transparente, no más opaco, el hecho de que la realización humana es recíproca. Este artículo no pretende demostrar que esto es posible. Sus pretensiones son más limitadas: pretende mostrar (a) que hay efectivamente una conexión interna entre órdenes espontáneos y libertad, por lo que esos órdenes son políticamente valiosos (esta conexión es la que exige rechazar el principio portaliano), pero (b) que nada en esa conexión implica que los órdenes espontáneos necesiten descansar en una representación de los intereses de cada individuo en la que ellos están en contradicción, por lo que (c) es (en principio) perfectamente posible diseñar órdenes espontáneos bajo los cuales los individuos aprendan que la realización humana es recíproca, en el sentido de que aprendan que sus intereses no están en conflicto. Esta última tesis se defiende en la parte final de este artículo, por referencia al problema de la organización de un sistema educacional en un país como Chile: después de explicar las características fundamentales del régimen institucional de la educación en Chile, que organiza ese sistema como uno en el cual los intereses de los individuos están en conflicto, muestra que un sistema como ése podría ser organizado de modo que la unidad de los intereses de todos se haría transparente. Para hacerlo no es necesario abolir el mercado. Como veremos, habría que radicalizarlo.

No es parte del artículo que lo que es posible en el caso de la educación es también posible en todos los ámbitos. Es posible que la 
educación tenga características peculiares que impiden que lo que puede correctamente decirse respecto de su organización institucional valga también para la provisión de servicios básicos o las relaciones laborales (aunque yo creo que el argumento es aplicable, con modificaciones menores, al problema de la organización institucional de la provisión de servicios de salud). Éste es el sentido más importante en que este artículo es programático. Muestra que un socialismo de órdenes espontáneos ("hayekiano") no es incoherente y que en una importante esfera es en concreto posible. Habiendo hecho eso, deja abierta la posibilidad de que en otras esferas sea también en concreto posible.

\section{Socialismo hayekiano}

Después de haber terminado una versión preliminar de este artículo que ya incluía su título descubrí que éste no era original. En efecto, en 1999 Richard Epstein publicó un artículo denominado "Hayekian Socialism" 20 . Epstein, sin embargo, usa esa expresión en un sentido distinto del de este artículo. Epstein creía que Hayek había hecho demasiadas concesiones al enemigo, y que como consecuencia se había declarado partidario de políticas socialistas (el caso que preocupaba especialmente a Epstein era el de lo que hoy llamaríamos una "red de protección social", que como veremos Hayek creía que era o podía ser inocua). Contra esta idea de Hayek, Epstein cree que "la crítica hayekiana se aplica a las concesiones hayekianas respecto de derechos mínimos de bienestar"21. Ése no es el sentido en el que uso la expresión "socialismo hayekiano". Por "socialismo hayekiano" aquí entiendo una determinada comprensión de la idea socialista y un modo de alcanzarla. La comprensión de la idea socialista que está detrás del argumento de este artículo fue explicada, aunque sólo someramente, en la sección anterior. Que ella puede ser alcanzada a través de estrategias hayekianas (a través de órdenes espontáneos) es el tema del resto del artículo.

La segunda crítica de Epstein a Hayek es más interesante en el contexto del argumento de este artículo. Epstein cree que Hayek había "exagerado nuestra ignorancia de las prácticas sociales generales" 22 .

\footnotetext{
${ }^{20}$ Epstein, "Hayekian Socialism".

${ }^{21}$ Ibid., 299.

22 Ibid., 281.
} 
Así, por ejemplo, Epstein discute el problema de si los estándares de riesgo permitido en actividades peligrosas deben ser fijados por la ley o por las partes mediante contratos. Epstein acepta el punto hayekiano de que la determinación de cuál es el riesgo aceptable depende de consideraciones que el legislador no puede anticipar ni conocer. Pero la cuestión es si esto implica que el legislador debe abstenerse de fijar un estándar de riesgo permitido, dejándolo entregado a la contratación de las partes. Dicho de otro modo, dice Epstein,

La cuestión central, sin embargo, es cuán lejos podemos llevar esta observación básica. Alguien tiene que elegir las reglas, y ni los jueces ni los legisladores usan la estrategia de ensayo y error que caracteriza a los órdenes espontáneos. A cierto nivel tenemos que tener cierta confianza respecto de ciertas regularidades empíricas generales si hemos de decidir qué regla debe ser preferida a otra. No queremos adoptar una regla de aplicación general en virtud de la cual los individuos nunca fueran responsables cuando mutilan extraños o maltratan pacientes. Asumimos esta posición no porque no estemos conscientes de la ignorancia humana, sino porque tememos los efectos del auto-interés humano sin límites. El que se queda con todo el beneficio sin cargar parte de las pérdidas probablemente realizará demasiadas actividades peligrosas, con independencia de las refinadas diferencias que ocurran entre temperamentos individuales y situación social. Así, la ignorancia debe ser insertada dentro de una teoría más general para poder elegir dentro de una lista de potenciales reglas generales y abstractas ${ }^{23}$.

Más adelante veremos la relevancia de esta observación de Epstein acerca de la exageración hayekiana de nuestra ignorancia. Por ahora es importante mencionar sólo el hecho de que lo que aquí entenderé por "socialismo hayekiano" no es lo que Epstein significa con la misma expresión, porque en el artículo de Epstein (pero no es éste) "socialismo" es un término de abuso.

Para explicitar en qué sentido lo que discutiremos en este artículo puede ser denominado "socialismo hayekiano" debemos volver a Law, Legislation and Liberty. Más arriba se ha explicado que ahí Hayek defendía, en lo que nos interesa ahora, dos ideas: la primera era que lo que Adam Smith llamaba "la gran sociedad" preservaba la libertad por

${ }^{23}$ Ibid., 281-282. 
descansar en órdenes espontáneos, no en órdenes creados; la segunda era que la justicia social era un espejismo. Hayek creía (y ésta es la idea que es hoy de sentido común) que estas dos observaciones estaban relacionadas: que la idea de justicia social no tenía sentido alguno aplicada a los órdenes espontáneos, por lo que si queremos perseguir la justicia social debemos abandonar los órdenes espontáneos y reemplazarlos por mandatos directos. En otras palabras, el argumento de Hayek que nos interesa ahora podría ser expresado de la siguiente manera:

1. Los órdenes espontáneos garantizan libertad, mientras que los órdenes creados la amenazan; o, dicho de otro modo, hay una conexión interna entre órdenes espontáneos y libertad.

2. La idea de "justicia social" (o: igualdad) carece radicalmente de sentido cuando se aplica a los órdenes espontáneos y sus resultados.

3. Por consiguiente hemos de optar por preservar los órdenes espontáneos (es decir la libertad) o perseguir la igualdad.

Esta tesis recibe apoyo adicional por el hecho de que concuerda con otra idea que también ha devenido sentido común, que a veces es designada "pluralismo de valores" y se asocia con la observación (que fue ofrecida como tal, sin argumento alguno en su apoyo ${ }^{24}$ : su éxito a pesar de esto muestra que es parte del "sentido común") de Isaiah Berlin de que los valores (en particular la libertad y la igualdad) están en conflicto, de modo que no podemos pretender alcanzarlos todos. Berlin, por alguna razón que vale la pena estudiar, ha alcanzado el status especial que se les reserva a ciertos autores que están más allá de las categorías políticas normales, lo que implica que el pluralismo de valores es hoy discutido como si fuera políticamente neutral, pese a que sus consecuencias políticas son evidentes. Y así estamos de vuelta en la observación anterior: entender que la libertad y la igualdad son incompatibles, y que nuestras prácticas políticas deben adecuarse a esa observación, es haber alcanzado un nivel de madurez del que el utopista que no acepta esto por ahora carece.

${ }^{24}$ En "Dos Conceptos de Libertad", Berlin da por establecido lo que denomina "pluralismo" del siguiente modo: "me parece que la creencia de que en principio pueda encontrarse una única fórmula con la que puedan realizarse de manera armónica todos los diversos propósitos de los hombres es demostrablemente falsa [is demonstrably false]. $\mathrm{Si}$, como yo creo, éstos son múltiples y todos ellos no son en principio compatibles entre sí, la posibilidad de conflicto y tragedia no puede ser nunca eliminada por completo de la vida humana, personal o social" (Berlin, "Dos Conceptos de Libertad", 179). 
No estoy ironizando cuando hablo de que una idea es parte del sentido común. Al contrario, el sentido común suele ser una fuente extraordinariamente fértil de sabiduría, si es leído correctamente. El sentido común es el destilado de adaptaciones más o menos irreflexivas que hacemos fruto de la experiencia adquirida al enfrentarnos a un mundo que se resiste a nuestros esfuerzos. Por lo tanto es un punto de partida sólido para la reflexión política. Por supuesto, no se trata de que por eso uno deba aceptarlo como indiscutible. De lo que se trata es que no puede ser simplemente desechado como irrelevante: incluso cuando es falso, el hecho de que sea "sentido común" es políticamente relevante ${ }^{25}$.

El problema del que trata este artículo es que la idea de sentido común que estamos considerando está conformada por dos observaciones: la primera es que hay una conexión interna entre órdenes espontáneos y libertad; la segunda es que, entonces, intervenir con los órdenes espontáneos es sacrificar libertad, y por consiguiente que no podemos intervenir con ellos a menos que lo hagamos de modos limitados. Proveyendo, por ejemplo, una especie de "red de seguridad" que asegure un mínimo de subsistencia a aquéllos cuyo desempeño en las esferas regidas por los órdenes espontáneos no sea exitoso. Una intervención más extensa con los órdenes espontáneos arriesga la libertad. En otras palabras: perseguir la igualdad como ideal político arriesga la libertad. Lo que podemos hacer es perseguir la eliminación de la pobreza, pero nada más.

Una manera en que este argumento es usualmente respondido es simplemente negándolo: negando, por ejemplo, que los órdenes espontáneos tengan una conexión interna con la libertad. Es característico de alguna cultura de izquierda, hoy completamente marginalizada y automarginalizada, rechazar la idea de que los órdenes espontáneos (cuyo paradigma es, desde luego, el mercado) crean libertad. Ellos creen que el mercado no es un espacio de libertad sino de explotación. Pero a mi juicio, si algo hemos aprendido en el siglo $\mathrm{XX}$ es que en eso, en que había una conexión interna entre órdenes espontáneos y libertad, Hayek tenía razón. El problema es que la idea misma de que hay una conexión interna entre órdenes espontáneos y libertad quedó, en nuestras (al menos en nuestra) culturas políticas, estrechamente vinculada a la idea de que la pregunta por la justicia social en general, o la igualdad en particular, es políticamente improcedente respecto de esos órdenes. Aquí

${ }^{25}$ Véase Atria, “¿Qué Educación es “Pública?”, 46-49. 
quiero explorar estas dos ideas no porque crea que el argumento de Hayek sobre el "espejismo" de la justicia social es un argumento digno de ser rebatido (no alcanza a serlo, como veremos) sino para disolver esta conexión y reclamar la idea de órdenes espontáneos de las manos de sus defensores neoliberales o (más peligrosamente) cripto-neoliberales, para una política que, en el sentido ya explicado, podría ser descrita con el nombre de "socialismo". De ahí "socialismo hayekiano".

\section{LA NOCIÓN DE ORDEN ESPONTÁNEO}

Aunque es la idea central de la trilogía Law, Legislation and Liberty, la noción de orden espontáneo utilizada por Hayek no es clara. O mejor dicho, es super-abundante, en el sentido de que Hayek ofrece al menos tres caracterizaciones distintas de esta idea. De eso se sigue que Hayek usa la expresión "orden espontáneo" en tres (o al menos dos) sentidos. Y el problema es que en uno de estos sentidos la noción sirve para justificar su tesis sobre la inaplicabilidad de la noción de justicia para sus resultados, mientras otro es el que muestra que los órdenes espontáneos protegen la libertad. El argumento formulado en la sección anterior, entonces, descansa en la confusión entre estos dos sentidos. Analizar las diferentes caracterizaciones de los órdenes espontáneos es lo que nos permitirá detectar el error en que incurre Hayek al sostener que la protección de la libertad es incompatible con la eliminación de la desigualdad, que igualdad y libertad están en conflicto.

\section{La idea de "orden"}

Antes de comenzar ese análisis, sin embargo, es necesario detenerse en la noción de "orden". ¿Qué es, precisamente, un "orden" del que entonces podamos preguntarnos si es o no "espontáneo"? Lo que debe ser clarificado aparece cuando consideramos un pasaje que será examinado más adelante con cierta detención, en el que Hayek distingue entre "un orden" y "las reglas en que descansa" 26 . Esta distinción sugiere que la relación entre un orden y sus reglas es la que existe entre un edificio y sus cimientos (o el terreno en el que está construido). Si

${ }^{26}$ Véase el pasaje infra, en el texto que acompaña n.31. 
esto fuera así, sería claramente un error sostener que el orden es reducible a sus reglas, por lo que una descripción de las reglas no sería una descripción del orden (del mismo modo que una descripción de los cimientos del edificio no es una descripción del edificio). La analogía muestra adicionalmente que la distinción contenida en el pasaje mencionado no discrimina en cuanto a considerar a las reglas parte del orden: los cimientos de un edificio son parte del edificio, pero no puede decirse lo mismo del terreno "en el que descansa". Pero ahora hemos de ignorar esta última complicación y concentrarnos en la primera observación (porque veremos que su solución solucionará también la segunda cuestión). ¿Qué relación hay entre un orden y sus reglas?

Hayek caracteriza la idea de "orden" de la siguiente manera:

Por 'orden' describimos aquí un estado de cosas en el cual una multiplicidad de elementos de varios tipos están relacionados de manera tal entre ellos que al conocer una parte espacial o temporalmente delimitada del todo podemos desarrollar acerca del resto expectativas correctas, o al menos expectativas que tienen una buena probabilidad de ser correctas $^{27}$.

Para ver la conexión entre la idea de orden y la idea de regla es necesario evitar cometer el error de creer que una regla es una formulación lingüística dada formalmente por una autoridad a través de un procedimiento determinado. Es evidente que las reglas pueden surgir sin necesidad de autoridades con potestad para crear reglas mediante el ejercicio de poderes a través de procedimientos preestablecidos. Si una regla se entiende como el sentido de un acto de autoridad es claro que no puede decirse que el orden sea igual a sus reglas, porque del hecho de que haya orden no se sigue que haya reglas en ese sentido (y, recíprocamente, del hecho de que haya reglas en ese sentido no se sigue que haya orden). Pero de la idea misma de orden se sigue que sólo hay orden cuando hay regularidad (de modo que a partir de nuestro conocimiento de un elemento podemos formarnos expectativas probablemente correctas acerca de otros). Esa regularidad puede tener su origen en prácticas no reflexivas que surgen "espontáneamente” (por eso la observación anterior: la existencia de un orden no necesita la existencia de reglas dadas por la autoridad).

${ }^{27}$ Hayek, Rules and Order, 36 (énfasis omitido). 
Neil MacCormick ha mostrado que una práctica institucional como el derecho puede ser entendida como una progresiva institucionalización de prácticas informales (irreflexivas) ${ }^{28}$. Su ejemplo inicial es el de una cola. Una cola es una práctica social, que existe porque un conjunto de personas tiene la práctica de ordenar la provisión de un bien o servicio, cuando es demandado por muchos, de acuerdo al orden de llegada. En tanto orden, una cola es entonces un conjunto de creencias o disposiciones de personas. Pero las colas pueden institucionalizarse: como nota el propio MacCormick, en las colas que se organizan en aeropuertos o estaciones, primero, la cola deja de ser un hecho físico (varias personas paradas unas detrás de otras) y pasa a ser un orden de prioridad adscrito a tickets numerados; esto crea nuevos problemas, como el de determinar qué ocurre con el que no se presenta cuando su número es llamado, sino que aparece después. Estos nuevos problemas pueden ser solucionados por reglas dotadas de autoridad. Hay una evidente continuidad entre colas informales, que surgen espontáneamente, y colas altamente institucionalizadas, regidas por reglas dadas por quien es respecto de ellas la autoridad a cargo, y sujetas al control de un funcionario que tiene autoridad para decidir las controversias que ocurran con ocasión de ellas. Más adelante veremos que esto presenta un problema para la caracterización de los órdenes espontáneos, porque pareciera que las primeras son espontáneas en un sentido que las segundas no lo son, aunque en otro sentido ambas son órdenes espontáneos. Pero ahora lo que nos interesa es la relación entre el orden y sus reglas. La razón por la que esta relación puede parecer problemática es que tratándose de colas institucionalizadas (es decir, del segundo tipo descrito más arriba) uno podría decir que hay colas porque hay reglas, mientras que tratándose de colas informales (del primer tipo) uno tendría que decir que hay reglas porque hay colas.

En esta sección es importante notar dos puntos. El primero es que si usamos "regla" en un sentido tal que pueda incluir reglas "implícitas" (como las de las colas informales) entonces que haya orden es que haya reglas. Como lo dice el propio Hayek,

Los ejemplos de órdenes espontáneos que hemos tomado de la física son instructivos porque ellos muestran claramente que las reglas que gobiernan la acción de los elementos de tales órde-

${ }^{28}$ MacCormick, Institutions of Law, 21-26. 
nes espontáneos no necesitan ser reglas 'conocidas' para esos elementos; es suficiente que los elementos realmente se comporten de un modo que puede ser descrito por esas reglas. Por consiguiente, en el sentido en que lo usamos en este contexto, el concepto de reglas no implica que esas reglas existen en formas articuladas ('verbalizadas'), sino sólo que es posible descubrir reglas que las acciones de los individuos de hecho siguen. Para enfatizar esto hablamos ocasionalmente de 'regularidad' más que de reglas, pero regularidad, por supuesto, significa simplemente que los elementos se comportan de acuerdo a reglas ${ }^{29}$.

Con el caveat de que las reglas pueden ser reglas implícitas, este primer punto es que los conceptos de reglas y de orden son coextensivos; o dicho de otro modo, que un orden es reducible a las "reglas que los individuos de hecho siguen".

La segunda observación es que parece tentador decir que los dos conceptos de regla distinguidos más arriba (reglas como el resultado del ejercicio de poderes institucionales y reglas como descripciones de clases de acciones, que pueden ser realizadas sin que los agentes estén conscientes de la existencia de la regla) corresponden a los dos conceptos de orden (creado y espontáneo, respectivamente). Aunque es posible que esta observación valga en una dirección (es decir, que la idea misma de órdenes creados requiera de reglas conscientemente formuladas), lo que resultará crucial es que no vale en el otro: es incorrecto decir que un orden es "espontáneo" cuando sus reglas son reglas implícitas, y no conscientemente creadas. Pero esto es discutir no la noción genérica de "orden", sino la específica de "orden espontáneo", lo que comenzaremos a hacer en la sección siguiente.

\section{Órdenes espontáneos como órdenes que surgen espontáneamente}

La caracterización inicial de un orden espontáneo (de hecho, la que es insinuada por el propio nombre) hace referencia a su modo de origen. Aquí la distinción entre órdenes creados y órdenes espontáneos es una distinción entre "dos formas diversas en que los órdenes pueden originarse" 30 : hay órdenes que son el resultado de decisiones deliberadas y órdenes que no lo son. Éste es el sentido en el que Hayek utili-

\footnotetext{
${ }^{29}$ Hayek, Rules and Order, 43.

${ }^{30}$ Ibid., 35.
} 
zará, en el segundo volumen de la trilogía, la idea de orden espontáneo para mostrar que la expresión "justicia social" carece de sentido. Como la justicia se predica de las acciones humanas, y las desigualdades distributivas que el mercado produce son el resultado de la interacción espontánea (en el sentido de no deliberadamente queridas por nadie) la idea misma de justicia es inaplicable a dichas desigualdades.

Pero la idea de orden espontáneo no puede limitarse a este sentido. Ello porque, en términos de resultados finales, un orden espontáneo (en el sentido de no deliberadamente producido) y uno "creado" no necesitan distinguirse. Así, por ejemplo, fue necesaria la idea darwiniana de la evolución natural de las especies para descartar el llamado "argumento del diseño" como un argumento para probar la existencia de Dios. El argumento era precisamente que los organismos vivientes tenía una estructura cuya misma complejidad era prueba de que habían sido conscientemente diseñados por una inteligencia divina. Pero ahora sabemos que, aunque los organismos vivientes parecen diseñados, no lo han sido. Esto, sin embargo, no es aprehensible mirando sólo al resultado.

La cuestión puede generalizarse notando que, desde el punto de vista del orden (es decir, del sistema de reglas o de regularidades improbables en que el orden consiste: nótese que, con las prevenciones introducidas en la sección anterior, éstas son sólo dos maneras alternativas de describir el orden) el hecho de que en su origen haya habido alguien que lo pensó y lo creó es externo a él, no dice nada acerca del tipo de orden que es en cuanto al modo en que funciona. Y si la idea de orden espontáneo ha de estar conectada internamente con la de libertad, es al funcionamiento del orden, no a un dato externo sobre su origen, a donde debemos mirar.

Esto, de hecho, es algo que el propio Hayek se ve forzado a reconocer, aunque pone en cuestión su propio argumento respecto del "espejismo" de la justicia social (y por eso esta idea desaparece del segundo volumen de Law, Legislation and Liberty). Enfrentado al hecho de que un orden espontáneo puede ser legislado, Hayek sostiene que

es necesario distinguir el carácter espontáneo del orden resultante del origen espontáneo de las reglas en las que descansa, y es posible que un orden deba ser descrito como espontáneo a pesar 
de descansar en reglas que en su totalidad fueron deliberadamente diseñadas ${ }^{31}$.

La relevancia de este punto es considerable, pero por ahora debemos notar que es imposible negarlo. El proceso de codificación, por sólo citar el caso más evidente, tanto en Francia como en Chile, pretendía dar al mismo viejo derecho común (civil), que es en términos hayekianos la formulación de las reglas de órdenes espontáneos, un fundamento nuevo, pero no pretendía transformar los órdenes espontáneos en órdenes creados. De hecho, en la medida en que cambió el derecho, lo hizo para suprimir particularismos locales y "mejorar" las reglas de los órdenes espontáneos. Al menos en Francia, parte importante del impulso al movimiento codificador estuvo dado por la idea de que las reglas necesitaban un fundamento de validez distinto al del derecho medieval. Ese fundamento de validez era ahora la voluntad del pueblo. El hecho de que las reglas fueran dictadas conscientemente, con el ánimo preciso de crear las condiciones para la emergencia de un orden espontáneo, no priva a ese orden de su carácter espontáneo ${ }^{32}$. El punto aceptado (a regañadientes) por Hayek es en realidad crucial: nada en la idea de orden espontáneo exige que la espontaneidad del orden deba ser entendida en sentido genético. Pero entonces parece que la distinción entre ordenes deliberadamente construidos y órdenes espontáneamente surgidos era una partida en falso, solamente destinada a fundar luego la idea de que los resultados de los órdenes espontáneos no son susceptibles de ser, por no tratarse de resultados imputables a la voluntad de alguien, calificados de justos o injustos. Todavía necesitamos saber cuál es la propiedad de esos órdenes que los hace ser "espontáneos" incluso cuando sus reglas ("las reglas en las que descansan") son deliberadamente diseñadas.

${ }^{31}$ Ibid., 46. Éste es el pasaje aludido en la sección anterior, donde Hayek hace una distinción entre "el orden (espontáneo)" y "las reglas en las que descansa". Por las razones explicadas entonces, esta distinción es puramente estilística, lo que además es demostrado por el hecho de que Hayek en otros casos habla de "las reglas que gobiernan las acciones de los elementos de tales órdenes espontáneos" (véase el texto que acompaña la n. 29) o "las reglas que determinan un orden espontáneo" (ibid., 43. Todos los destacados en esta nota son agregados).

${ }^{32}$ Para la tensión entre un régimen legal (el de los códigos civiles decimonónicos, incluido el nuestro) cuyo contenido es en el sentido relevante "espontáneo" aunque su fundamento es la voluntad del soberano (art. $1^{\circ} \mathrm{CC}$ ), véase Atria, "La Relevancia del Derecho Civil". 


\section{Órdenes espontáneos como órdenes cuyos resultados son imprevisibles}

Más cercano a lo que necesitamos como caracterización está la segunda vía elegida por Hayek: por referencia a la posibilidad de prever y controlar las particulares manifestaciones del orden:

Lo que muestra que incluso un orden que descansa en reglas creadas puede ser de carácter espontáneo es el hecho de que sus manifestaciones particulares siempre dependerán de circunstancias que el creador de esas reglas no sabía ni podía saber ${ }^{33}$.

Veremos más adelante que esta característica es mucho menos obvia de lo que parece, porque todo dependerá del nivel de detalle en el cual busquemos anticipar los resultados de un orden (dicho de otro modo: como "general" y "particular" son conceptos que admiten graduaciones, la cuestión será cuán particulares son las manifestaciones particulares que no pueden ser anticipadas). Por ahora, sin embargo, debemos notar que la imprevisibilidad de sus resultados no puede ser lo que define a un orden espontáneo, sino (en el mejor de los casos) una consecuencia de sus propiedades características. Dicho de otro modo, el hecho de que X "muestre" la naturaleza de Y no implica que X defina $\mathrm{Y}$, sino sólo que es su manifestación más conspicua. Por consiguiente, si lo que "muestra" que un orden es "espontáneo" es que sus manifestaciones particulares son impredecibles eso tiene que ser superviniente respecto de alguna característica propia del orden.

Dicho de otro modo, el solo hecho de que las manifestaciones particulares del orden sean imprevisibles para su creador no puede ser directa y primitivamente (en vez de indirecta y derivadamente) relevante. Después de todo, hay muchas razones por las cuales los resultados de los órdenes creados pueden resultar imprevistos. Si la imprevisibilidad de los resultados de un orden es teóricamente relevante, debe tratarse de una imprevisibilidad que no sea consecuencia de, por ejemplo, limitaciones epistémicas propias de un creador particular o de sus circunstancias. Debe ser una imprevisibilidad que se funde en una característica propia del orden (del cual podamos decir entonces: es espontáneo). Y será esa característica la que nos permitirá entender la espontaneidad del orden, sin perjuicio de que, si la correlación entre esa característica y la imprevisibilidad es suficientemente estrecha, podamos usar la se-

\footnotetext{
${ }^{33}$ Hayek, Rules and Order, 46.
} 
gunda como criterio de identificación (del mismo modo que, por ejemplo, usamos la firma de una persona en un documento para concluir que ese documento representa la voluntad del firmante. Lo que nos interesa es la voluntad, y la marca en el papel la usamos como criterio para identificar la voluntad. Pero sería un error decir que la firma es el consentimiento. No, la firma cumple la función que la imprevisibilidad cumple aquí: sólo "muestra" que ha habido expresión de voluntad).

Recuérdese, en todo caso, que lo que Hayek pretende es establecer una vinculación entre órdenes espontáneos y libertad. Desde este punto de vista, es claro que la sola imprevisibilidad de los resultados del orden no alcanza a fundar dicha conexión. Y nótese adicionalmente que la conexión que Hayek reclama haber encontrado es interna, no contingente: no se trata (o no se trata sólo) de que estadísticamente haya más libertad bajo órdenes espontáneos, sino que hay algo en la noción de orden espontáneo que se conecta con la preservación de la libertad. Y la imprevisibilidad de los resultados de los órdenes no parece ser un candidato razonable para fundar esa conexión interna.

Por consiguiente hemos de seguir buscando. Pero ahora, podemos aprovecharnos de la pista que nos da Hayek al decir que los resultados de los órdenes espontáneos son imprevisibles. ¿Qué los hace imprevisibles?

\section{Las reglas de los órdenes espontáneos}

Lo dicho al final del párrafo anterior implica que del hecho de que la imprevisibilidad de sus manifestaciones particulares no pueda ser tomada como un criterio definitorio de los órdenes espontáneos no se sigue que ella sea enteramente irrelevante. Al contrario, podemos tomarla por ahora como una marca perspicua de esos órdenes, y buscar una explicación para esto. La razón por la que las manifestaciones particulares de los órdenes espontáneos son imprevisibles es una característica de sus reglas, y es esa característica la que nos importa ahora.

Para apreciar la característica que nos interesa podemos comenzar considerando un notable pasaje de Adam Smith en la Theory of Moral Sentiments, en el que el propio Hayek encuentra "algunos de los términos y conceptos básicos"34 del argumento desarrollado en el volumen primero de Law, Legislation and Liberty:

\footnotetext{
${ }^{34}$ Ibid., 155.
} 
El hombre de sistema [...] pretende aplicar [su plan ideal de gobierno] completamente y en todas sus partes, sin atención alguna a los grandes intereses ni a los fuertes prejuicios que puedan oponérsele. Él se imagina que puede organizar los diferentes miembros de una gran sociedad con tanta facilidad como organiza las piezas de ajedrez en el tablero. No considera que las piezas en el tablero no tienen un principio de movimiento distinto del que su mano le impone. Pero en el gran tablero de ajedrez de la sociedad humana, cada pieza individual tiene un principio de movimiento propio, completamente independiente del que el legislador pueda elegir imponerle. Si estos dos principios coinciden y actúan en la misma dirección, el juego de la sociedad humana procederá tranquila y ordenadamente, y es muy probable que sea feliz y próspero. Si son opuestos o diferentes, el juego procederá lastimosamente, y la sociedad estará en todo momento en el grado más alto de desorden ${ }^{35}$.

La idea de Smith es que los individuos tienen sus propios principios de movimiento (hoy hablaríamos de finalidades, o intereses). La "gran sociedad" es una en la que el legislador no les exige a los individuos abandonar dichos fines, y un orden espontáneo es un orden dentro del cual lo que guía a los individuos no necesita ser la finalidad (el principio de movimiento) legislativo, sino sus propios fines. Esto porque las reglas de los órdenes espontáneos son tales que ellas pueden ser "aplicadas por los individuos a la luz de sus propios conocimientos y propósitos", porque su aplicación es "independiente de cualquier propósito común, que el individuo no necesita conocer"36.

Los órdenes espontáneos, entonces, son órdenes compuestos por reglas cuya aplicación es independiente de los propósitos o finalidades del creador de esas reglas. Ésta es la característica definitoria de dichos órdenes, en tanto conceptualmente primitiva respecto de las otras, y es la que puede explicar las dos caracterizaciones fallidas anteriores como corolarios, más o menos necesarios.

La primera, recuérdese, era que los órdenes espontáneos eran órdenes que surgían espontáneamente. Ahora estamos en condiciones de decir: como los individuos no necesitan perseguir otras finalidades que las propias para ser exitosos en términos del orden, un orden espontáneo puede surgir sin que nadie lo haya creado deliberadamente

\footnotetext{
${ }^{35}$ Smith, The Theory of Moral Sentiments, secc. 6.2.42.

${ }^{36}$ Hayek, Rules and Order, 50.
} 
(=el orden no es lógicamente anterior a ninguna acción). Puede surgir, dicho de otro modo, como una ordenación emergente de las acciones de individuos cada uno de los cuales persigue sus propios fines. Esto es en principio posible porque no es necesario que cada agente se forme una opinión sobre la finalidad del orden mismo para actuar exitosamente en términos del orden. En consecuencia, el solo hecho de que haya orden no implica por sí mismo la existencia de una autoridad que deliberadamente lo ha creado, del mismo modo que después de Darwin podemos desechar el "argumento del diseñador" que sobre la base de la existencia de organismos vivos complejos concluía que Dios, como diseñador de esos organismos, debía existir. Pero nótese aquí la diferencia entre decir que la existencia del orden prueba que no existe diseño deliberado y decir que la existencia del orden no prueba la existencia de un diseñador. La primera afirmación es injustificada, la segunda es correcta.

En segundo lugar, como las reglas de los órdenes espontáneos son tales porque ellas no exigen a los agentes que, para actuar exitosamente en términos del orden, abandonen sus propios principios de movimiento y adopten los principios del orden, las manifestaciones concretas del orden son consecuencia del modo en que cada agente aprovecha las posibilidades de acción dentro del orden para perseguir sus fines. Esto explica la brecha entre las reglas del orden y sus manifestaciones concretas en que se funda la imprevisibilidad notada por Hayek. Por lo mismo, esto explica la mayor aptitud del orden para adaptarse a circunstancias cambiantes, y de ese modo dar cuenta en principio de cualquier grado de complejidad y de cualquier déficit en la información de cada uno de sus miembros: las acciones no necesitan ser decididas de antemano por una autoridad central (que entonces requeriría reunir toda la información relevante antes de decidir), sino son la consecuencia de decisiones adaptativas descentralizadas, cada una de ellas tomada por individuos que usan la información de la que disponen para perseguir sus propios fines de la mejor manera posible ${ }^{37}$.

${ }^{37}$ Este es el famoso argumento "epistemológico" de Hayek contra la planificación central, expresado originalmente en textos como Hayek, "The Use of Knowledge in Society" y Hayek, "Economics and Knowledge" (ambos reimpresos, ahora, en Hayek, Individualism and Economic Order). Lo que comenzó siendo un argumento acerca de las limitaciones del conocimiento humano y sus consecuencias, y en particular el sistema de precios como un sistema extraordinariamente económico de transmisión de la informa- 
Es importante destacar el carácter derivado de estas dos observaciones, en virtud del cual debemos estar siempre conscientes de que el hecho de que ellas se obtengan en un caso es un indicio de que tratamos con un orden espontáneo, aunque es en principio posible que se trate de un orden espontáneo pese a que ninguna de estas dos observaciones sea verdadera. Lo realmente decisivo (lo que explica la conexión entre la idea de órdenes espontáneos y libertad) no es ni la génesis del orden ni la previsibilidad de sus manifestaciones particulares. Es una característica de sus reglas, el hecho de que su aplicación es independiente de las finalidades legislativas.

Por último, es también importante notar que el argumento hasta ahora sólo ha establecido que los órdenes espontáneos son órdenes cuyas reglas son susceptibles de ser seguidas exitosamente sin perseguir la finalidad del orden. Pero aquí de nuevo es importante notar la diferencia entre decir que esas reglas deben carecer de propósitos comunes (lo que el argumento hasta ahora no justifica decir) y que esas reglas deben poder ser aplicadas sin tener a la vista su propósito. El argumento de Smith sólo justifica esta segunda afirmación, y entonces no excluye órdenes espontáneos formados por reglas que tienen una finalidad común. En este último caso, la exigencia es sólo que las reglas sean tales, que el individuo pueda actuar exitosamente bajo ese orden persiguiendo su propio principio de movimiento.

\section{ÓRDENES ESPONTÁNEOS Y LIBERTAD: LA CONEXIÓN INTERNA}

El entusiasmo de Hayek por los órdenes espontáneos le hace exagerar sus atributos de los dos modos que hemos visto. Pero eso no debe llevarnos a ignorar la relevancia de esa idea. Y para eso es importante tener presente dos limitaciones de los órdenes creados en relación con los espontáneos. En ellas está la vinculación interna entre órdenes espontáneos y libertad.

En un orden creado, el orden es un instrumento de su creador para alcanzar alguna finalidad. Pero esa finalidad del creador se alcanza sólo en la medida en que los individuos hacen lo que el creador del

ción que los agentes en el mercado necesitan para decidir qué o cuánto producir, terminó en el argumento sobre órdenes espontáneos que estamos discutiendo en este artículo. Importante como este argumento es, sin embargo, no es necesario detenerse en él, porque nada de lo dicho en este artículo lo niega. En algún sentido, de hecho, el argumento de este artículo descansa en el argumento epistémico de Hayek. 
orden les ordena. Dicho de otro modo, el cumplimiento de la finalidad del (creador del) orden sólo es posible en la medida en que los individuos abandonan sus principios individuales de movimiento y persiguen los del legislador, por la vía de cumplir sus mandatos directos. Eso explica dos características (supervinientes) de los órdenes creados: en primer lugar, que están siempre en principio expuestos a lo que podríamos denominar corrupción, esto es, a la persecución de finalidades privadas a expensas de las finalidades del orden. Para evitar (o disminuir) el riesgo de corrupción, el orden creado debe limitar las posibilidades del agente de actuar de modos imprevistos, y debe sujetarlo al cumplimiento de órdenes concretas. La necesidad de actuar de acuerdo a estas órdenes concretas impide que el individuo al que se dirigen use su propio conocimiento y juicio para enfrentar las condiciones en las que se encuentra de la manera más adecuada para conseguir las finalidades del orden. Por eso, los órdenes creados no pueden procesar más información de la que está disponible y puede ser procesada por el creador del orden. Crucialmente, no pueden aprovecharse de los ajustes descentralizados realizados espontáneamente por quienes deben aplicar las reglas a la luz de la información de la que sólo ellos disponen, porque no hay garantía de que esos ajustes perseguirán la finalidad del orden y no la de los individuos. Ésta era la objeción de Hayek contra la economía centralmente planificada ${ }^{38}, \mathrm{y}$ es difícil hoy negar que el argumento es correcto.

En segundo lugar, los órdenes creados, precisamente porque exigen a los individuos que abandonen sus principios de movimientos y adopten el del creador del orden, arriesgan transformar a los individuos en instrumentos para realizar la finalidad legislativa. A diferencia de ellos, los órdenes espontáneos descansan en individuos que persiguen sus propios fines. Desde el punto de vista del orden (y veremos lo importante que es esta calificación de perspectiva) los individuos no son instrumentos, sino fines.

Es por eso que la eficacia de los órdenes creados necesita reconstruir al individuo. Y esto, por supuesto, es la mayor amenaza a la libertad. Como ya se ha discutido más arriba, aquí el riesgo a la libertad es que la necesidad de re-construir al individuo lleva a negar la relevancia de los individuos realmente existentes (el "principio portaliano").

${ }^{38}$ Véanse los artículos mencionados supra, n. 37, especialmente Hayek, "The Use of Knowledge in Society". 
Como ya se ha sostenido, es probablemente este riesgo el que está en el origen del denominado "pluralismo" 39 .

Hayek explicaba estas dos limitaciones de los órdenes creados diciendo que ellos tenían finalidades, mientras que los órdenes espontáneos carecían de ella, por no haber sido creados:

no habiendo sido creado, no puede decirse legítimamente que un orden espontáneo tiene un propósito particular [it cannot legitimately be said to have a particular purpose], aunque nuestra conciencia de su existencia puede ser extraordinariamente importante para que podamos perseguir exitosamente una gran variedad de finalidades diferentes ${ }^{40}$.

Lo dicho hasta ahora muestra la notoria falta de rigurosidad de la frase anterior al "aunque": ella es derechamente falsa, en el sentido de que el propio argumento de Hayek ha mostrado algo distinto. La frase debería decir: "no siendo necesariamente creado, puede decirse legítimamente que un orden espontáneo no necesita tener un propósito particular". Ahora, sin embargo, lo que nos interesa es la segunda parte (la que sigue al "aunque"). Ella contiene una ambigüedad en la expresión "nuestra", y como suele ocurrir con el texto de Hayek que estamos considerando buena parte del argumento se juega en esa ambigüedad ${ }^{41}$. El sentido de esa expresión que fluye del programa hayekiano mira a "nosotros" como agentes bajo un orden espontáneo (como el mercado). Entendida así, la afirmación significa que saber cuáles son las reglas del mercado puede resultarnos, a cada uno de nosotros, extremadamente útil para que podamos perseguir exitosamente nuestros propios fines en el mercado. Esta comprensión es la que aparece, por ejemplo, cuando Hayek sostiene que un orden espontáneo "no puede tener un propósito" porque no ha sido deliberadamente diseñado, aunque "hay un propósito en la acción de sus elementos". Pero aquí, en rigor, el uso de la idea de "propósito" es estrictamente incorrecto, y debe ser entendido como una metáfora como la que es habitual en biología evolutiva: una "abreviación teleológica" que

\footnotetext{
${ }^{39}$ Véase el texto de Berlin citado supra, en el texto que acompaña la n.16.

${ }^{40}$ Hayek, Rules and Order, 38.

${ }^{41}$ Sobre la confusión de perspectivas en la que descansa esta ambigüedad, véase Atria, "La Verdad y lo Político (i)", 32-33.
} 
es inofensiva en la medida en que no implica conciencia del propósito por parte de los elementos del orden, sino sólo que los elementos han adquirido regularidades de conducta que conducen al mantenimiento del orden - probablemente porque los que actuaron de ciertos modos tuvieron dentro del orden existente una mayor probabilidad de supervivencia que los que no lo hicieron $^{42}$.

Es difícil exagerar las conclusiones que Hayek obtendrá de esta idea, por lo que es útil notar cuidadosamente los pasos del argumento. El primero es que el orden espontáneo no ha sido deliberadamente creado por nadie. Por consiguiente, no tiene, en sentido estricto, una finalidad o propósito. La idea de propósito puede ser utilizada metafóricamente, como cuando un biólogo dice que tal o cual mutación genética tenía el "propósito" de aumentar la adaptación de una determinada característica y de ese modo maximizar la tasa de reproducción de un determinado gen. Pero esto es sólo una manera estrictamente impropia de describir la situación. La evolución de los órdenes espontáneos no es conducida por una finalidad que los tira hacia ella, sino por mecanismos de filtro y presión adaptativa que los empujan hacia un punto que, cuando conocemos la racionalidad del orden, podemos quizás describir genéricamente (e.g. un fenotipo capaz de alcanzar una tasa relativamente alta de reproducción), pero no en sus "manifestaciones concretas".

Como un orden espontáneo en el sentido relevante carece de propósito, lo que resulte de la interacción de los elementos del orden, actuando bajo él, no puede decirse que sea la consecuencia de una acción deliberada de nadie. Y esto a su vez implica que las categorías de justo e injusto no les son aplicables a los resultados de los órdenes espontáneos:

Como sólo las situaciones que han sido creadas por la voluntad humana pueden ser calificadas de justas o injustas, los resultados particulares de un orden espontáneo no pueden ser justos o injustos: si el hecho de que A tenga mucho y B tengo poco no es el resultado buscado o previsto de la acción de alguien, esto no puede ser calificado como justo o injusto. Veremos que lo que se denomina justicia "social" o "distributiva" carece de hecho de significado dentro de un orden espontáneo y tiene sentido sólo dentro de una organización ${ }^{43}$.

\footnotetext{
${ }^{42}$ Hayek, Rules and Order, 39.

${ }^{43}$ Ibid., 33.
} 
Aquí vemos la estructura del argumento, que vincula las dos ideas mencionadas al principio: los órdenes espontáneos garantizan la libertad, porque permiten a cada individuo perseguir sus fines y no les imponen la obligación de abandonarlos para hacer suyos fines determinados por la autoridad; pero precisamente porque lo que guía a los individuos son sus propios fines, y no fines legislativamente determinados, los resultados que se sigan de la agregación de las acciones de los diversos individuos actuando bajo las reglas de un orden espontáneo no son queridos por nadie. No son, en otras palabras, imputables a ninguna voluntad particular. Este hecho es de extraordinaria importancia. Hayek concede que los resultados producidos por el mercado serían injustos si ellos fueran imputables a una voluntad humana ${ }^{44}$, pero que no siéndolo tienen, como hemos visto, la relevancia política de las catástrofes naturales o las incapacidades congénitas: podrá ser bueno o malo que una persona sea ciega mientras que la siguiente no lo es, pero no puede decirse que sea injusto a menos que supongamos que la diferencia es el resultado buscado o al menos anticipado de alguna acción intencional de alguien.

El argumento hayekiano nos deja, entonces, en la siguiente disyuntiva: o reconocemos la conexión interna entre órdenes espontáneos y libertad, y por consiguiente entendemos que las brutales desigualdades que nos son tan familiares son resultados no imputables a la voluntad de nadie, por lo cual no puede decirse con sentido que sean más justas o injustas que el hecho de que un pueblo y no otro sea arrasado por la erupción de un volcán, o rechazamos la conexión entre órdenes espontáneos y libertad, asumiendo que los términos fundamentales de la interacción social deben determinarse mediante la creación de una enorme organización que distribuya oportunidades y recompensas mediante órdenes creados, asignando a cada individuo una función dentro de esa organización e ignorando que los individuos que forman parte de ese orden tienen un principio de movimiento distinto del que ese orden requiere que los guíe. A pesar de lo cauto que uno debe ser en estos casos para no dar por verdadero lo que en buena parte puede ser propaganda, es difícil no ver en la opción por la segunda vía el origen del hecho paradójico de que una teoría política de la libertad y la emancipación haya inspirado las dis-topías conocidas con el nombre de "socialismos reales". Y el hecho de que buena parte de la izquierda lo haya

${ }^{44}$ Ibid., 64. 
visto, junto a la constatación de que ellas eran efectivamente dis-topías, explica nuestra situación actual.

En efecto, el significado político del derrumbe del muro de Berlín fue la constatación de que en esta alternativa no podemos sino elegir la primera opción. Y elegir la primera significa declarar que la desigualdad producida por el mercado (en tanto desigualdad) es políticamente irrelevante. Desde luego, esto no significa que quienes han tenido poca suerte en el mercado deban quedar entregados a su suerte, del mismo modo que no hay razón por la que quienes hayan visto sus casas destruidas por la erupción de un volcán no puedan esperar alguna cooperación de parte de quienes han resultado ser más afortunados. Como lo dice Hayek,

no hay razón por la cual en una sociedad libre el gobierno no deba asegurar a todos cierta protección contra las privaciones más severas en la forma de un ingreso mínimo asegurado, o un piso bajo el cual nadie puede descender. Aceptar un seguro de este tipo contra el infortunio extremo puede bien ir en el interés de todos: o puede sentirse que es un deber moral de todos asistir, a través de la comunidad organizada, a aquellos que no pueden ayudarse a sí mismos. En tanto tal ingreso mínimo uniforme sea provisto fuera del mercado a todos los que, por cualquier razón, son incapaces de ganar en el mercado un ingreso suficiente, esto no necesita ser una restricción de la libertad, o estar en conflicto con el Estado de derecho ${ }^{45}$.

Pero por supuesto, la condición de esta red de protección es que ella no interfiera con el orden del mercado, por lo que una finalidad superior a compensar por las privaciones más severas sí sería incompatible con la libertad y el Estado de derecho.

Y ésta es nuestra situación actual. Una situación en que la aspiración igualitaria, al entenderla como incompatible con la libertad, ha sido reemplazada por una caritativa preocupación por la pobreza. Pero nótese que en buena parte esto no es sino un caso de reducción de disonancia cognitiva, es decir, de convencernos de que no debemos siquiera aspirar a lo que no sabemos cómo lograr. Porque como ha sostenido perceptivamente Gerald Cohen, intentando explicarse el hecho de que el esfuerzo de construir prácticas políticas igualitaristas haya hasta el momento fracasado,

${ }^{45}$ Ibid., 87. Sobre la justificación de este piso mínimo, véase Atria, "Sobre la Soberanía y lo Político". 
Nuestro problema no es, primordialmente, el egoísmo humano, sino nuestra carencia de una tecnología organizacional apropiada: nuestro problema es un problema de diseño [...] Es que, aunque sabemos cómo hacer funcionar un sistema económico sobre la base del egoísmo, no sabemos cómo hacerlo funcionar sobre la base de la generosidad, aun cuando en el mundo real, en nuestra propia sociedad, muchas cosas dependen de la generosidad o, para ponerlo de un modo más general y negativo, no dependen de incentivos de mercado ${ }^{46}$.

Y lo que quiero explicar en la próxima sección es que, irónicamente, es en la obra de Hayek (o, estrictamente, como veremos, de Adam Smith) donde debemos empezar a buscar la "tecnología institucional de la igualdad" que nos falta.

\section{CONSTRUCTIVISMO "INGENUO"Y "REALISTA"}

Para apreciarlo, debemos volver a la ambigüedad que decía puede encontrarse en la expresión de Hayek transcrita más arriba. Se trataba, recuérdese, del sentido de la expresión "nuestra" en una frase que será útil citar de nuevo:

no habiendo sido creado, no puede decirse legítimamente que un orden espontáneo tiene un propósito particular, aunque nuestra conciencia de su existencia puede ser extraordinariamente importante para que podamos perseguir exitosamente una gran variedad de finalidades diferentes ${ }^{47}$.

Hemos visto cuál es la interpretación de la frase destacada que corresponde al proyecto político hayekiano. Pero en rigor, la interpretación que se ciñe al argumento como ha sido considerado, y no como a Hayek le habría gustado, puede bien ser distinta. En esta segunda interpretación, anti-hayekiana, el "nuestra conciencia" no hace referencia a la conciencia de cada uno de nosotros en tanto agentes bajo un orden espontáneo, sino a nosotros en tanto ciudadanos, es decir, en tanto comunidad política. Esta interpretación debe ser llamada "anti-hayekiana" porque sin duda contiene precisamente la idea que Hayek quería combatir del modo más categórico, la que para él es una instancia de lo que

\footnotetext{
${ }^{46}$ Cohen, "Por Qué No el Socialismo", 77-82.

${ }^{47}$ Hayek, Rules and Order, 38 (destacado agregado).
} 
llamaba "constructivismo ingenuo": la idea de que los términos en los que vivimos en el mundo no sólo individual sino también colectivamente son susceptibles de ser afectados por nuestras decisiones conscientes acerca de cómo sería bueno o adecuado que viviéramos. Pero esta objeción hayekiana a la idea de auto-gobierno se desvanece enteramente cuando notamos, como lo hemos hecho, que en rigor no hay nada en la noción de orden espontáneo, en tanto orden propio de una sociedad libre, es decir, en cuanto a su conexión interna con la libertad, que exija que esa espontaneidad deba ser entendida genéticamente o que niegue que los órdenes espontáneos pueden tener un propósito o finalidad, y que en consecuencia muestre que el "constructivismo" es incompatible con la libertad.

Como individuos actuando bajo un orden espontáneo, el orden se nos presenta como ajeno, como parte del mundo, y nuestra acción debe ajustarse a él para ser exitosa. Como ciudadanos, sin embargo, el orden es una parte de nuestras condiciones de vida, y no hay razón en principio por las que no pueda ser modificado. No hay en el argumento de Rules and Order razón alguna para negar esto, aunque él sí implica que no pueden ser modificadas de cualquier modo. Es a través de la modificación y manipulación de las reglas sobre las que descansa un orden espontáneo que podemos modificar nuestras formas de vida. Esta idea de que las condiciones bajo las que vivimos están en principio sujetas a nuestra acción (es decir: puedan ser conscientemente modificadas), pero no de cualquier manera, explica el "corto retraso" al que hace alusión Proudhon en la carta que sirve de epígrafe a este artículo. El punto es importante, por lo que conviene reiterarlo: Hayek no tiene argumento en contra del "constructivista" que cree que modificando las reglas sobre las que descansa un orden espontáneo (en vez de reemplazándolo por uno creado) podemos lograr nuestras finalidades en cuanto a alcanzar formas más humanas de vida.

Para apreciar la importancia de este punto, es interesante considerar algunas instancias en las que, mediante la modificación o manipulación de las reglas en las que descansa o las condiciones en que opera un orden espontáneo es posible obtener una finalidad que no se obtendría "espontáneamente" (es decir, sin dicha modificación o manipulación $)^{48}$. El primero se refiere al paradigma de orden espontá-

48 Los dos ejemplos que consideraremos aquí son también discutidos por Epstein, "Hayekian Socialism”, 274-288. 
neo, la evolución por selección natural de las formas biológicas complejas. La "mejor idea jamás pensada", de hecho, fue introducida por Darwin a través de la discusión de la selección no natural sino artificial: la de "la variación en estado doméstico" 49 . Aquí es derechamente imposible negar que "nuestra" conciencia del modo en que opera el orden espontáneo puede resultar "extremadamente importante" para obtener alguna finalidad aprovechándose de las características del orden. Y nótese que aquí el "nuestra" hace referencia, al modo "constructivista", no a los elementos del orden, sino a ganaderos y agricultores que buscaban mejorar las especies domésticas, por la vía de manipular el orden espontáneo.

Es común en la izquierda mirar al darwinismo (o más especialmente al neodarwinismo) con desconfianza. En algún sentido esto es extraño, porque después de todo, como lo notó Engels en la tumba de Marx, hay un evidente paralelo entre el darwinismo como teoría de la evolución de las especies y el materialismo histórico como teoría de la evolución de las formas sociales y los modos de producción. Ahora podemos ver, en un sentido distinto, que la posibilidad de usar órdenes espontáneos para obtener nuestras finalidades colectivas (al modo "constructivista") no es refutada sino afirmada por el propio Darwin. Pero aunque extraña, esta desconfianza no es enteramente infundada: el neodarwinismo actual pretende dar un fundamento "natural" a la idea hobbesiana del individuo, a la tesis de que una explicación fundamental de "por qué somos como somos" 50 muestra que el dato básico de la "naturaleza humana" es que nuestros intereses están en conflicto, y que en esas circunstancias, creamos lo que creamos, lo que hacemos es siempre explotar al prójimo. Esta tesis, por supuesto, no es darwinismo sino neoliberalismo ${ }^{51}$.

\footnotetext{
${ }^{49}$ Éste es el título y el tema del capítulo 1 de Darwin, The Origin of Species, 1554. "La variación en la naturaleza" es el título y tema del capítulo 2.

${ }^{50}$ Éste es, de hecho, el subtítulo del libro de Fischer, La Mejor Idea Jamás Pensada.

${ }^{51}$ Nótese la liviandad con la que alguien como Fischer pasa de la observación de que el "altruismo" en términos evolucionarios sólo es adaptativo si deja de ser altruismo (es decir, si es lo que suele denominarse "altruismo recíproco") a una afirmación sobre lo que explica la conducta de los seres humanos: "las personas tienen conductas altruistas con terceros porque esperan conductas recíprocas en el futuro, esto es, esperan ser ellas quienes reciban beneficios de parte de quienes ya los recibieron" (ibid., 125). Sin notar en ningún momento la contradicción en que incurre, Fischer continúa: "así, llevamos una especie de 'cuenta corriente' de los actos de altruismo ofrecidos y recibi-
} 
El segundo caso que puede invocarse como ilustración de que no hay nada en la idea de orden espontáneo que excluya lo que Hayek denomina "constructivismo" es el de la Constitución norteamericana. Como lo explica Hamilton en el primer escrito de The Federalist Papers, el sentido de la dictación de la Constitución de los Estados Unidos fue

decidir la importante cuestión de si las sociedades de hombres son realmente capaces o no de establecer el buen gobierno a través de la reflexión y la elección, o si ellas están destinadas a depender para sus constituciones políticas en accidente y fuerza ${ }^{52}$.

La Constitución misma es un orden que no sólo tiene finalidades, sino que las declara al principio ${ }^{53}$. Y la idea que guía ese orden no es el de reemplazar el orden espontáneo por un orden creado, sino construir sobre los intereses y finalidades anticipables de cada uno, con la finalidad de alinear el interés individual y el interés general:

dos" (ibid., 179). Aquí uno podría decir, como Bentham de Blackstone: "con relación a otros, puede que sea una afirmación demasiado absoluta; pero en lo que a él mismo se refiere, con conocimiento de causa, no tenemos por qué dudarlo" (Bentham, "Fragmento sobre el Gobierno", II.29, nota). Para rechazar esta suerte de neo-hobbesianismo no es necesario seguir la estrategia (oscurantista) de negar la idea de evolución natural o su aplicación al ser humano. Basta negar la pretensión absurda de que si la mente y el lenguaje evolucionaron espontáneamente el ámbito del significado y del sentido es sólo una pantalla, algo que desfigura y esconde lo que verdaderamente es el caso (un "velo", como lo llama Fischer): "el lenguaje de la máquina ("la lógica evolucionaria que guía nuestras conductas") es el que instruye la interacción de nuestro organismo con el medio, pero nosotros lo percibimos ya compilado por nuestro sistema de emociones" (ibid., 129). La pregunta es en qué sentido ese "lenguaje de la máquina" guía nuestras conductas, qué nos enseña acerca de nosotros mismos. Como ha observado notablemente Raymond Gaita, “¿nos dirán las teorías evolucionarias del altruismo siquiera algo sobre la naturaleza de la compasión por el que sufre, sobre su pureza cuando está libre de toda traza de condescendencia, o sobre su poder de revelar la humanidad de aquéllos cuya aflicción ha hecho invisible su humanidad? Cuando alguien nos pida reflexionar sobre lo que hemos hecho al traicionar a un compañero que confió en nosotros, o al apoyar políticas asesinas por adhesión irreflexiva a nuestro país, o al dar dinero a un mendigo con evidente condescendencia, ¿recurriremos a la teoría evolucionaria para entender?" (Gaita, The Philosopher's Dog, 179).

52 Hamilton, Madison y Jay, The Federalist Papers, $§ 1$.

${ }^{53}$ El preámbulo de la Constitución de 1787 es un ejemplo evidente de "constructivismo", pese a lo cual está en la base de la "civilización desconocida que está creciendo en América" a la que Hayek dedicó The Constitution of Liberty: "We, the people of the United States, in order to form a more perfect Union, establish justice, insure domestic tranquility, provide for the common defense, promote the general welfare, and secure the blessings of liberty to ourselves and our posterity, do ordain and establish this Constitution for the United States of America". 
Pero la mayor garantía contra una concentración gradual de los diversos poderes en el mismo departamento consiste en dar a quienes administran cada departamento medios constitucionales necesarios y motivos personales para resistir la usurpación por los otros. Los medios de defensa deben ser, en este y en todos los otros casos, proporcionales al peligro del ataque. Es necesario hacer que la ambición contrarreste la ambición ${ }^{54}$.

Dicho de otro modo, no se trata de crear un orden constitucional que imponga a cada agente un deber que debe entonces ser cumplido por ese agente con independencia de sus intereses reales y concretos (es decir: no se trata de un orden creado); se trata, al contrario, de configurar institucionalmente la posición de cada agente de modo que lo que vaya en su interés sea además lo que preserva la estructura del orden. Se trata, en otras palabras, de crear, "a través de la reflexión y la elección", un orden espontáneo.

Uno podría entonces aprovecharse de la etiqueta derogatoria de Hayek y entender que, si el "constructivismo ingenuo" es el constructivismo del que cree que nuestras formas políticas pueden ser reemplazadas completamente por otras que responden a algún diseño deliberado, a la manera del "hombre de sistema" del que hablaba Adam Smith, el constructivismo que por eso sería entonces "realista" es el que acepta la tesis de Smith pero la rechaza cuando ella recibe su interpretación hayekiana. Desde el punto de vista de este "constructivismo realista", el punto importante de Smith no tiene relación alguna con la idea hayekiana de que la aplicación de la idea de justicia social a los resultados de un orden espontáneo es un error categorial. Precisamente al contrario, lo que Smith está indicando en ese pasaje es cuál es la forma en que es razonable perseguir finalidades colectivas que son en efecto distintas de las finalidades que guían a los elementos del orden. Nos da la primera pista de la tecnología socialista que Cohen echa de menos. Para verla, debemos rechazar (por dogmática) la lectura de Hayek conforme a la cual la tesis de Smith era que el legislador no puede tener un principio autónomo de movimiento, y entenderla en el sentido de que especifica el modo en que el principio legislativo puede ser perseguido sin comprometer la libertad.

En efecto, Hayek lee a Smith como si éste sostuviera que dado que las piezas individuales de ajedrez, en el gran tablero de la sociedad humana, tienen un principio propio de movimiento, el legislador debe

\footnotetext{
${ }^{54}$ Hamilton, Madison y Jay, The Federalist Papers, $§ 51$.
} 
renunciar a perseguir una finalidad que no sea la de permitir a los individuos que persigan sus propias finalidades. Pero Smith sostiene que la gran sociedad es posible en la medida en que el principio legislativo y el principio de movimiento de cada pieza "coinciden y actúan en la misma dirección". No tiene sentido decir que A y B han de "coincidir y actuar en la misma dirección" si A desaparece y queda sólo B. Debemos entonces detenernos en la idea de que el principio legislativo y el individual "coinciden y actúan en la misma dirección”, y contrastar esta situación con el caso patológico de que ellos resultan ser "opuestos o diferentes".

Para apreciar estas dos cuestiones debemos volver a la distinción entre órdenes espontáneos y creados. Recuérdese: como bajo un orden espontáneo la finalidad del orden se alcanza cuando los individuos que actúan bajo él lo hacen persiguiendo sus propios intereses, no se presenta la oposición, propia de los órdenes creados, entre la finalidad del orden y la finalidad del agente. Esto implica, por una parte, que el orden puede beneficiarse del conocimiento del individuo de sus circunstancias concretas, y del modo en que en ellas es mejor desplegar los medios a su alcance para obtener sus fines. Por lo mismo, el individuo no es utilizado como un medio para obtener la finalidad legislativa: el orden supone que sus fines son importantes, y no que debe abandonarlos para perseguir una finalidad que le puede resultar ajena.

¿Qué quiere decir que los principios de movimiento coincidan? Recordemos lo que hemos visto que Hayek decía acerca de (lo que aquí he llamado) la conexión interna entre órdenes espontáneos y libertad: las reglas de un orden espontáneo deben ser tales que ellas han de poder ser aplicadas por los individuos sin referencia a su propósito común. Hayek, lo hemos visto, creía que esto es lo mismo que sostener que las reglas deben carecer de un propósito común. Pero espero que ya estemos inmunizados contra este virus dogmático-ideológico de Hayek. Todo lo que es necesario para mantener la conexión interna entre orden y libertad es que los órdenes bajo los cuales los individuos deben llevar adelante sus planes de vida han de ser tales que no les exijan que, para ser exitosos, abandonen sus finalidades y adopten finalidades que a ellos aparecen ajenas, las del orden. El principio legislativo (el "propósito común" cuya ausencia Hayek creía que caracterizaba a los órdenes espontáneos) "coincide" con el principio propio de movimiento de cada una de las piezas individuales cuando el primero es susceptible de ser alcanzado de dos vías: mediante individuos actuando conforme a sus 
propios principios de movimiento, es decir, individuos para los cuales el principio legislativo no funciona como guía, y mediante individuos que han hecho suyo el principio legislativo, es decir, para los cuales no hay oposición entre el principio legislativo y el individual. Nótese que, en estas condiciones, carece de sentido que un individuo adopte el principio legislativo por razones estratégicas (es decir, que se deje guiar por él a pesar de que no lo haya hecho su fin), y por eso puede decirse que el orden trata a los individuos como fines. La razón por la cual carece de sentido esta conducta estratégica del individuo es que no es necesaria: no es más exitoso el individuo que actúa persiguiendo su propia finalidad que el que actúa persiguiendo el fin legislativo. Pero el individuo puede actuar persiguiendo su propia finalidad, y no es penalizado por eso. Por consiguiente, si el individuo actúa persiguiendo el fin legislativo ya no hay pérdida para la libertad: ya no puede decirse que ese fin le sea ajeno. Ahora es su fin.

\section{EL CASO DE LA EDUCACIÓN}

Quiero ahora ejemplificar el argumento anterior y mostrar algunas de sus consecuencias por referencia al caso de la educación en Chile ${ }^{55}$. Nuestro sistema educacional es lo que podría denominarse un sistema mixto, en el cual intervienen proveedores de distintos tipos: establecimientos fiscales, establecimientos particulares subvencionados y establecimientos privados no subvencionados (que suelen ser denominados "particulares pagados"). Los fundamentos de este sistema se encuentran en los números 10 y 11 del artículo 19 de la Constitución: conforme al primero, la Constitución asegura a todas las personas "el derecho a la educación"; conforme al segundo, asegura "la libertad de enseñanza"56.

\section{Un sistema mixto en cuanto a sus criterios de distribución: mercado y ciudadanía}

La garantía del derecho a la educación se concreta, legislativamente, en la existencia de un sistema público compuesto por provee-

${ }^{55}$ Esta sección descansa en el argumento mucho más detallado y extenso contenido en Atria, Mercado y Ciudadanía en la Educación.

${ }^{56}$ Sobre la interpretación de los números 10 y 11 del artículo 19 de la Constitución, véase ibid., 41-64. 
dores estatales ante los cuales los ciudadanos pueden concurrir como quien ejerce su derecho, es decir, que no pueden negarse a admitirlos ${ }^{57}$. Como todos los ciudadanos tienen derecho a la educación, esta categoría sirve de garantía: si una persona no satisface las condiciones que los demás establecimientos exigen como criterios de admisión, siempre ha de haber un establecimiento público que esté obligado a admitirlo. Los establecimientos de la educación llamada "particular" (privada) pueden ser subvencionados o no. Los primeros reciben, como su etiqueta lo indica, una subvención estatal que implica que ellos no necesitan cobrar a sus estudiantes una suma de dinero que se transforme entonces en condición de acceso. Originalmente, de hecho, estos establecimientos tenían prohibición legal de exigir contraprestación monetaria alguna a sus estudiantes o sus padres. Los establecimientos de la educación "particular pagada" se financian con los aportes de los padres. Tratándose de ellos el establecimiento puede exigir la contraprestación económica que juzgue necesaria.

El sistema es mixto en el sentido de sus criterios de distribución $n^{58}$ : el reconocimiento del derecho a la educación implica que al menos en el sistema público la educación se distribuye de acuerdo a un criterio de ciudadanía: todos tienen derecho a ser educados, por lo que el establecimiento no está en la posición del que puede condicionar la admisión. Pero sobre este nivel, todos tienen libertad de enseñanza, lo que quiere decir que pueden, si así lo desean y tienen los medios para eso, contratar privadamente en el mercado la educación que prefieran. La mixtura del sistema chileno es la coexistencia de los criterios de mercado y ciudadanía como criterios de distribución del bien educacional.

El sistema tiene un aspecto inconfundiblemente hayekiano: en primer lugar, asume que la educación es en principio una cuestión que cada uno ha de procurarse con cargo a sus recursos. Pero como hemos visto que no hay razón por la cual no sea razonable que los ciudadanos decidan contratar políticamente un seguro contra la privación extrema (en la forma de una "red de seguridad"), el Estado asume la obligación de organizar un sistema gratuito de educación. Ahora bien, esta obligación asume exactamente la forma que defendía Hayek, como un

${ }^{57}$ Para esta caracterización de la educación "pública”, véase Atria, “‘QQué Educación es 'Pública'?".

${ }^{58}$ Sobre la diferencia entre mercado y ciudadanía como criterios de distribución, véase Atria, Mercado y Ciudadanía en la Educación, 80-85. 
subsidio a la demanda, en lo que suele conocerse como un sistema de "vouchers" (es recibida por establecimientos municipales y particulares subvencionados en función de su matrícula, por referencia al promedio mensual de asistencia) ${ }^{59}$. Recuérdese que la condición de Hayek para que esta red de seguridad fuera compatible con la libertad y el Estado de derecho era que ella asumiera la forma de un "ingreso mínimo provisto fuera del mercado a todos los que, por cualquier razón, son incapaces de ganar en el mercado un ingreso suficiente" 60 . El sistema de vouchers conforme al cual se financia la educación pública y la privada subvencionada es una suerte de ingreso mínimo educacional que el Estado concede a todo ciudadano que quiera utilizarlo. La provisión se realiza al margen del mercado, pero su uso es a través del mercado (por eso es un sistema de subsidio a la demanda).

\section{La tendencia "espontánea” a la segregación}

El sistema puede ser descrito como un orden espontáneo, en la medida en que el criterio de asignación de estudiantes a establecimientos se basa en la regla del artículo $19 \mathrm{~N}^{\circ} 10$ inciso $3^{\circ}$ de la Constitución: "Los padres tienen el derecho preferente y el deber de educar a sus hijos". Esto quiere decir que la distribución de estudiantes en establecimientos no responde al diseño de alguien que ha creado el sistema, sino a la elección de los padres, que es guiada por sus propios principios de movimiento. Para tener claridad sobre la diferencia, podemos decir que organizar el sistema educacional como un orden creado supondría reglas que especificaran a qué establecimiento debe asistir cada estudiante. La política norteamericana de busing, encaminada a producir la integración racial de las escuelas de algunos estados de Estados Unidos después de la decisión de la Corte Suprema en Brown v. Board of Education, es quizás un buen ejemplo. La práctica del busing supone que el sistema, al menos a cierto nivel, se basa en mandatos que definen, con prescindencia de los intereses concretos de cada agente,

${ }^{59}$ Es un error, aunque común, sostener que el sistema público chileno es un subsidio a la oferta. El régimen de financiamiento de los establecimientos privados subvencionados y municipales es el mismo: reciben una cantidad determinada calculada sobre la base de los estudiantes que están matriculados en ellos. Los estudiantes (sus "padres") tienen libertad para elegir el establecimiento, y el financiamiento que el Estado provee se dirigirá al establecimiento en que los estudiantes se matriculen.

${ }^{60}$ Véase supra, el texto que acompaña a la n.45. 
el establecimiento educacional al que cada uno ha de asistir. Por contraste, un orden espontáneo no recurre a mandatos de ese tipo, sino a reglas que pueden ser aprovechadas por cada agente para perseguir sus intereses. Tengan o no tengan un propósito común, esas reglas pueden ser aplicadas por cada individuo a la luz de sus propios intereses y finalidades; a la luz, es decir, de lo que para cada uno es importante en la educación de sus hijos.

Aunque, como está dicho, originalmente el hecho de que un establecimiento recibiera subvención estatal implicaba que no podía cobrar adicionalmente a sus estudiantes, a poco andar se introdujo lo que se denominó "financiamiento compartido", en virtud del cual la subvención estatal se hizo compatible con un cobro de ese tipo, sujeto a ciertas condiciones. Es importante notar aquí que en algún sentido el argumento a favor del financiamiento compartido era irresistible: si al que puede pagar la educación de sus hijos (en la educación llamada "particularpagada") nada le impide hacerlo, ¿qué argumento había para negarle al que sólo podía pagar una parte que lo hiciera?

Esto produjo, por una parte, una expansión de la matrícula que ya ha alcanzado el $100 \%$ y, por otra, una progresiva segregación de clase. Cada estudiante va al establecimiento que su dinero puede pagar, ni un peso más abajo ni un peso más arriba. Para explicar este movimiento de expansión de la matrícula y de segregación de clase basta entender el funcionamiento de un sistema mixto como el chileno y el principio dominante de movimiento de los individuos que deben actuar bajo él. En realidad estas dos consecuencias de la configuración de un orden como espontáneo es, pace Hayek, algo que puede predecirse con un alto nivel de certeza cuando se introducen reformas de mercado (al menos si son exitosas): aumento de la riqueza y aumento de la desigualdad.

El punto de partida es el supuesto que funda la regla del inciso $3^{\circ}$ del artículo $19 \mathrm{~N}^{\mathrm{o}} 10$ de la Constitución: lo que esa regla llama "los padres" (que en rigor no necesitan ser los padres, pueden ser también otras personas que tienen la responsabilidad especial de velar por los intereses del menor) tienen el derecho y el deber de educar a sus hijos porque al elegir lo harán guiados predominantemente por lo que a su juicio es mejor para ellos. Es evidente que si este supuesto demostrara ser falso, y fuera el caso de que al elegir los padres utilizan a los hijos como instrumentos para perseguir, en perjuicio de éstos, sus propios 
fines, la regla del inciso $3^{\circ}$ debería ser revisada. El supuesto, sin embargo, no parece absurdo. Es parte de nuestra experiencia que el modo normal de comprensión de la relación entre padres e hijos menores de edad es tal que los intereses de los padres incluyen los intereses del hijo. Dado este supuesto, podemos anticipar que el principio dominante de movimiento de las decisiones que los padres deban tomar respecto de la educación de sus hijos será obtener la mejor educación posible para sus hijos. Es decir, que utilizarán los recursos que posean para mejorar la educación recibida por sus hijos, y que la finalidad de cumplir su función de padres será más fuerte, motivacionalmente hablando, que la finalidad (colectiva) de obtener, por ejemplo, un sistema integrado con educación de calidad suficientemente igual para todos.

Dadas las consideraciones anteriores (es decir, dada la estructura mixta del sistema educacional chileno y dado el hecho de que el principio dominante de movimiento de cada agente es obtener la mejor educación posible para sus hijos) es posible anticipar que el orden que resulte de la suma de las decisiones individuales tenderá a la segregación, tan rigurosa como sea posible.

Lo que es crucial aquí es entender que para que el sistema se segregue no es necesario que los agentes deseen un sistema segregado. Lo que cada uno busca es la mejor educación para sus hijos, pero lo que la suma de sus decisiones produce, en el contexto institucional chileno, es una progresiva segregación de clase. La segregación es el resultado de decisiones particulares que no buscan segregación.

El punto es en realidad obvio, y puede construirse en dos niveles. En primer término, es evidente que, ceteribus paribus, mientras más recursos se inviertan en educación mejor será la educación recibida. Por consiguiente, es obvio que, en la medida en que los "padres" tengan un interés en mejorar la educación de sus hijos, estarán dispuestos a pagar por hacerlo, y eso ya es suficiente para observar que, con el tiempo, los establecimientos se segregarán de acuerdo a su precio. En el diseño original del sistema educacional chileno, conforme al cual sólo los establecimientos de la educación particular pagada podían sujetar la admisión o permanencia a una contraprestación en dinero, esta segregación sólo podía ocurrir respecto de ellos. Con la introducción del financiamiento compartido, la segregación se hace más generalizada y más fina. 
Pero el punto anterior, obvio como es, no da cuenta de la dimensión del problema. La calidad de la educación recibida no es función sólo de los recursos monetarios invertidos en ella, sino adicionalmente del grupo con el cual un estudiante debe educarse. Esto tanto en términos estrictamente pedagógicos (el llamado "efecto de pares") como por las demás consecuencias o condiciones de la educación (la formación de "redes" sociales, el beneficio de un ambiente socialmente estable en el establecimiento, etc. ${ }^{61}$. Estas dimensiones adicionales hacen que a cada uno le sea beneficioso estudiar con personas que estén socialmente mejor ubicadas que uno, porque de ese modo es posible "mejorar" el grupo social de pertenencia y beneficiarse además del mayor capital cultural de los miembros de ese grupo socialmente "superior".

En efecto, como en general el hecho de que un individuo se eduque junto a otros de grupos socialmente "inferiores" no mejora sino empeora (en sentido lato) la calidad de la educación que recibe, las condiciones de selección de los establecimientos que están legalmente habilitados para seleccionar estudiantes tenderán a ordenarse de modo que cada uno se eduque junto a otros que son como él: no con los que pertenecen a grupos "superiores" a él (porque entonces éstos mejorarían su educación si pudieran excluirlo, por lo que iría en el interés de ellos moverse a un establecimiento que establezca condiciones de ingreso que lo excluyan), ni con los de grupos "inferiores" (por la razón recíproca).

En sentido lato, entonces, la calidad de la educación que un individuo reciba será superior si asiste a un establecimiento que establezca exigencias que permitan el ingreso sólo a personas como él o ubicadas en una posición socialmente "superior". Ahora bien, dado que la mixtura del sistema educacional chileno implica que hay establecimientos que no pueden sujetar el ingreso de sus estudiantes a condiciones (la educación pública en sentido estricto) y establecimientos que pueden condicionar discrecionalmente ese ingreso (la educación particular, subvencionada o no), es posible anticipar que el orden que resulte de la suma de las decisiones individuales tenderá a la segregación, tan rigurosa como sea posible.

${ }^{61}$ Para referirnos a la suma de ambos efectos podemos hablar de calidad de la educación “en sentido lato". La denominación es incorrecta en tanto califica la educación por efectos no educativos, pero es correcta en tanto toma en cuenta consideraciones que, a pesar de ello, son relevantes dado el principio de movimiento de los padres. 


\section{¿Puede decirse de la segregación que es injusta?}

Aquí podemos observar uno de los aspectos del argumento ya comentado de Hayek. ¿Puede decirse de un sistema educacional "espontáneamente" segregado que es injusto? Es evidente que, si se tratara del resultado buscado de una política estatal, la respuesta sería positiva. La segregación social de la educación es injusta en tanto permite al privilegiado transmitir su privilegio, reproduciendo en la siguiente generación la desigualdad de la que se beneficia. Adicionalmente, la diferencia de calidad en la educación (en sentido lato) que es la consecuencia necesaria de un sistema educacional segregado es particularmente dañina en sociedades meritocráticas de mercado, en las cuales las posiciones sociales de poder y prestigio son (o al menos se espera que sean) distribuidas en atención a méritos personales que son, al menos en una buena parte, consecuencias del tipo de educación recibida.

Esto hace que un sistema educacional segregado, que maximiza la transmisibilidad del privilegio, sea una fuente constante de injusticia. Una sociedad de mercado asume que la distribución producida por el mercado (al menos cuando el mercado funciona adecuadamente) no puede ser calificada de injusta porque lo que cada uno recibe es el reconocimiento de los otros a sus aptitudes y capacidades. Esto quiere decir que, si el mercado funciona adecuadamente, no hay injusticia en que A reciba 100 y $\mathrm{B}$ reciba 10 . Aquí que el mercado funcione adecuadamente quiere decir que $\mathrm{A}$ y $\mathrm{B}$ estuvieron en posición de competir y que en esa competencia A venció a B. La desigualdad de primera generación, desde este punto de vista, está justificada.

Pero en este contexto un sistema educacional segregado transforma la justicia en injusticia: en efecto, el sistema se encargará de de transformar desigualdades (por hipótesis justificadas) de primera generación en desigualdades injustificadas de segunda generación (o superior). Ello porque en esas condiciones A podrá usar sus 100 para asegurar el éxito de su hijo cuando a éste le llegue el momento de competir con el hijo de B. Como el hijo de A no puede haber hecho mérito alguno ${ }^{62}$, esa diferencia hace que ya no se pueda apuntar a los resultados de la competencia en el mercado para justificar desigualdad alguna.

${ }^{62}$ Esto es consecuencia de la inocencia radical de los niños: nada de lo que ellos hagan cuenta en contra de ellos (al respecto, véase Atria, Mercado y Ciudadanía en la Educación, 21). 
Pero en el caso chileno, sin embargo, la segregación del sistema escolar no es (por hipótesis) la consecuencia de una política deliberada. Al contrario, se trata de las consecuencias que, a nivel agregado, tiene la suma de decisiones individuales cada una de las cuales no busca segregar el sistema socialmente y menos causar el daño que la segregación causa (lo que los padres buscan es dejar a sus hijos en la mejor posición posible para enfrentar la vida, no reproducir una distribución injusta). El argumento de Hayek es que esto hace que debamos modificar dramáticamente nuestro juicio. Si antes decíamos que la segregación era injusta, ahora tendríamos que decir que ella es indiferente, que es algo de lo que no puede predicarse justicia o injusticia:

Por supuesto no nos equivocamos al percibir que los efectos de los procesos de una sociedad libre sobre la suerte de los diferentes individuos no son distribuidos de acuerdo a algún principio reconocible de justicia. Donde nos equivocamos es al concluir de esto que ellos son injustos y que alguien puede ser culpado por ellos ${ }^{63}$.

O, como lo dice de modo aún más enfático unas páginas antes,

Debe por supuesto admitirse que la manera en la que los beneficios y cargas son distribuidos por el mecanismo del mercado en muchos casos tendría que ser calificado como muy injusto si fuera el resultado de la distribución deliberada a personas particulares $^{64}$.

Pero de esto, dice Hayek, no se sigue que podamos decir que son injustos. Debemos considerar aquí las razones en virtud de las cuales es incorrecto decir que los resultados son consecuencia de la acción del que introdujo las reglas sobre las que descansa el orden o de aquél en virtud de cuya autoridad esas reglas se mantienen. Sólo porque en el sentido relevante, según Hayek, no podemos decir que la segregación sea consecuencia de las acciones del legislador ella no puede ser calificada de justa o injusta. Como hemos visto más arriba, el argumento es que la cadena de imputación se rompe porque entre la dictación o mantención de esas reglas y el resultado que se trata de calificar hay una brecha que es mediada por la acción de los individuos que persi-

\footnotetext{
${ }^{63}$ Hayek, Rules and Order, 69s.

${ }^{64}$ Ibid., 64 .
} 
guen sus propios fines, entre los cuales (por hipótesis) no está producir segregación. Es para crear esta brecha que Hayek pasa de constatar que los órdenes espontáneos no necesariamente tienen un propósito a concluir que ellos necesariamente deben carecer de un propósito. Pero esto es insostenible. Si bien los resultados particulares del orden son a cierto nivel impredecibles, es absurdo concluir de esto que al crear las reglas o al mantenerlas estamos totalmente en la obscuridad respecto de cuáles han de ser sus resultados: no estamos totalmente, sino sólo parcialmente, en la obscuridad. El envenenador no está totalmente en la obscuridad sobre las consecuencias de su acción de envenenar la reserva de agua por el hecho de que los resultados particulares de su acción (la individualización de los envenenados) sean impredecibles.

Por supuesto, no es suficiente decir que nuestra ignorancia es parcial, porque debemos preguntarnos si lo que sabemos es suficiente dado lo que nos interesa. El hecho de que el envenenador no pueda anticipar precisamente quiénes serán afectados hace a su acción irracional si lo que desea es envenenar a una persona en particular, pero no si lo que desea es causar terror en la población. Si nuestra pregunta es por la justicia de un sistema educacional que en virtud de su mixtura entre mercado y ciudadanía como criterios de distribución tiene una tendencia interna a la segregación social, el hecho de que no podamos especificar qué individuos precisamente han de ser perjudicados y qué individuos beneficiados no tiene por qué afectar nuestro juicio. No hay absolutamente nada objetable en decir (1) que, aunque no podemos predecir exactamente quién atenderá qué establecimiento, el hecho de que el sistema sea en el sentido explicado mixto implicará una tendencia interna a la segregación, por lo que (2) la mantención de las reglas que configuran un sistema mixto produce la segregación del sistema, de modo que puede decirse que la segregación es imputable a aquél por cuya autoridad el sistema mixto se mantiene. Así como sería insensato que aceptáramos la defensa del envenenador de que envenenar el agua no causa la muerte de nadie, porque entre la acción de envenenar el agua y el resultado de muerte hay una brecha que es mediada por la acción del que consume el agua (que ciertamente no quiere el resultado), el hecho de que la segregación sea mediada por la acción de individuos que no buscan segregar es irrelevante. 


\section{¿Es necesario restringir la libertad para acabar con la segregación?}

Pero quizás el argumento de la sección anterior podría ser concedido sin evitar la conclusión de que la segregación es políticamente inevitable. Quizás el argumento podría conceder, en otras palabras, que la segregación es injusta, pero enfatizar que ella sólo puede ser eliminada al precio de sacrificar la libertad. Este argumento es más importante que el anterior, porque es hoy políticamente más efectivo. Como ya está dicho, recibe apoyo adicional por la idea "pluralista" de que igualdad y libertad están en conflicto. Éste sería sólo un caso más de esas circunstancias en las que una sociedad libre exige tolerar grados más o menos considerables de desigualdad.

Aplicado al problema de la segregación del sistema educacional, podríamos decir que ella es consecuencia de que se trate de un orden espontáneo, que aquí quiere decir que es un orden que se basa en la libertad de los "padres" para elegir la educación de sus hijos. Eso, podría decirse, implica una tendencia interna a la segregación, por las razones ya explicadas. Para evitar la segregación sería necesario reemplazar este orden espontáneo por un orden creado, en que las plazas de los establecimientos educacionales fueran asignadas por un funcionario que actúa guiado por la finalidad del orden (proveer una educación socialmente integrada), y dirige mandatos concretos a individuos particulares (distribuyendo plazas entre establecimientos educacionales) para que éstos, abandonando sus propias finalidades, actúen según lo que desde el punto de vista del orden es conveniente.

Ésta es la manera en que la cuestión es habitualmente discutida en Chile. Aunque no suele decirse con esas palabras, se asume que al precio de la libertad de "los padres" de elegir establecimiento educacional es la desigualdad en la provisión de educación. En efecto, ya hemos visto que desde el punto de vista de la educación que cada uno recibe lo mejor es educarse con personas situadas en mejor o al menos igual posición social que la de uno, por lo que si los "padres" pueden libremente elegir el establecimiento eso llevará a la segregación del sistema. La conclusión está a la vista: para evitar la segregación es necesario acabar con la libertad de elegir. Libertad e igualdad están en conflicto.

Paradójicamente, la mejor manera de responder a este argumento es recurrir a la idea hayekiana de órdenes espontáneos, una vez que ella ha sido clarificada en la forma en que lo hemos hecho en la primera parte de este artículo. En términos de lo ya discutido, la tesis de que 
en un caso como el que estamos considerando la libertad y la igualdad están en conflicto necesita mostrar (a) que los órdenes espontáneos garantizan la libertad, y que los órdenes creados la niegan o en el mejor de los casos la arriesgan; (b) que en el caso que estamos considerando la desigualdad resultante (la segregación de clase) no puede ser eliminada sino aboliendo el orden espontáneo. El argumento de la primera parte muestra que la primera premisa es correcta, pero la segunda falsa. Como la segunda premisa es falsa, el argumento, que descansa en ambas, puede ser desechado.

En efecto, la segunda premisa se apoya en dos de las observaciones de Hayek: la primera, que lo que caracteriza a los órdenes espontáneos es que ellos son genéticamente espontáneos; la segunda, que los órdenes espontáneos no tienen un propósito, que (en términos de Adam Smith) un orden espontáneo es un orden caracterizado por el hecho de que no hay un principio legislativo de movimiento.

Pero ya sabemos que ambas observaciones son falsas. De la observación (correcta) de que los órdenes espontáneos no necesariamente tienen un creador no se sigue que ellos necesariamente no tienen un creador; y de la observación (correcta) de que los órdenes espontáneos permiten a los agentes actuar siguiendo sus propios principios de movimiento no se sigue que ellos no pueden responder, como orden, a ninguna finalidad o propósito. Ahora podemos apreciar que estas derivaciones inválidas no eran sólo errores en el argumento: eran necesarias para reclamar, para una ideología neoliberal (cuyo sentido, si se me permite decirlo ahora, no es ni proteger la libertad ni la igualdad, sino proteger el privilegio de los privilegiados) la forma institucional de la libertad.

Corregidas que sean estas falsas derivaciones, podemos decir que, en el sentido en el que los órdenes espontáneos protegen la libertad, ellos no necesitan ni ser de origen espontáneo ni carecer de un propósito. Todo lo que es necesario es que ellos sean órdenes en el contexto de los cuales los individuos no necesiten abandonar sus finalidades para adoptar las del orden. No hay razón alguna para entender que esto es posible sólo tratándose de órdenes que han surgido espontáneamente ni que para que esto sea el caso el sistema no debe tener una finalidad global.

Y tratándose del caso que nos ocupa aquí, el del sistema educacional chileno y su tendencia interna a la segregación (y en consecuencia a la desigualdad), es crucial notar que esa tendencia no se explica 
por el hecho de que el sistema permita a los individuos actuar persiguiendo sus propias finalidades (lo que ellos creen que es mejor para la educación de sus "hijos"). Si eso fuera efectivamente el caso, entonces la segregación sólo podría ser evitada reemplazando un orden espontáneo por uno creado, y el argumento de Hayek (y del "pluralista") sería correcto. Pero lo que hace que el sistema tenga una tendencia interna a la desigualdad es el hecho de que él permite que los individuos usen recursos desigualmente distribuidos para mejorar la educación de sus hijos. Para eliminar la tendencia a la desigualdad no es necesario reemplazar el orden por uno creado. Todo lo que es necesario es reducir el impacto que, en sus decisiones acerca de la educación de sus hijos, tienen recursos desigualmente distribuidos. En la medida en que los recursos que son utilizables para actuar en el orden son iguales, la tendencia a la desigualdad es neutralizada; es decir, es reemplazada por una tendencia contraria.

Eso es, por ejemplo, lo que explica la regla "una persona, un voto". Permitir que en los procedimientos de formación de voluntad política cada uno use sus recursos haría que esos procedimientos estuvieran sistemáticamente sesgados a favor de quienes tienen más recursos. La manera en que las instituciones políticas evitan este problema no es eliminando el voto (reemplazando los procedimientos de votación libre por decisiones de funcionarios), sino limitando los recursos que cada ciudadano puede usar para contribuir a la formación de la voluntad de todos. Los recursos se reducen a uno: su voto. Como los individuos sólo pueden usar un recurso que está igualitariamente distribuido para participar del proceso político electoral, la tendencia a la desigualdad que implica (por ejemplo) un sistema de voto censitario es neutralizada y reemplazada por una tendencia a la igualdad de influencia.

En el caso del sistema educacional podemos decir lo mismo. En la medida en que los individuos tengan diferentes dotaciones de recursos susceptibles de ser utilizados en la educación de sus hijos, el sistema educacional (es decir, el orden emergente de la suma de las decisiones descentralizadas de los individuos) tenderá a segregarse conforme a los recursos que cada individuo pueda invertir en la educación de sus hijos. No hay ninguna razón, aparte de la ceguera ideológica, para declarar que este resultado, una vez producido, era una consecuencia "impredecible" o "no anticipable". Cada decisión que modifica las reglas sobre las que descansa el sistema educacional, aumentando el 
impacto que pueden producir los recursos desiguales de los individuos, tiene el efecto perfectamente anticipable de aumentar correlativamente la segregación del sistema educacional, aun cuando no podamos anticipar la forma concreta de esa segregación. Un sistema educacional que se basa en la regla del inciso $3^{\circ}$ del $\mathrm{N}^{\circ} 10$ del artículo 19 (derecho de los padres a elegir la educación de sus hijos) puede ser un sistema que tienda a la igualdad en la medida en que los establecimientos educacionales no estén legalmente habilitados para seleccionar o en algún sentido condicionar la admisión de estudiantes. Esto no es limitar la libertad para obtener igualdad: es maximizar la libertad, porque hemos visto que en el sistema actual la libertad para elegir la educación de los hijos varía según la posición social del individuo (el que está más abajo no tiene libertad de elegir, porque sólo puede optar a los establecimientos que no establecen condiciones de ingreso). Tratándose del sistema educacional, la protección completa y radical de la libertad implica la protección completa y radical de la igualdad. Para esto bastaría con radicalizar y universalizar la política neoliberal de vouchers. En efecto, si (al modo del voto) todo ciudadano tuviera acceso a un voucher educacional, y si la educación no pudiera ser pagada con ningún otro recurso alternativo o adicional al voucher, y si la libertad de elegir de "los padres" recibiera máxima y radical protección (excluyendo la posibilidad de que un establecimiento neutralizara la elección de alguien por la vía de exigirle requisitos que no cumple), el sistema podría describirse como un orden espontáneo con una tendencia interna a la integración y por ende a la igualdad $^{65}$.

Si el argumento anterior es correcto, habremos de decir que la realización de la igualdad en el sistema educacional no supone la abolición de los órdenes espontáneos y su reemplazo por órdenes creados con mandatos concretos. Es posible que podamos configurar circunstancias en las que el interés de los individuos por obtener una educación mejor para sus hijos no está en conflicto con el interés legislativo (es decir, de los ciudadanos) en un sistema igualitario y no segregado. De hecho, en este caso, se trata de modificar las reglas en las que descansa el sistema educativo para eliminar (o al menos reducir) el impacto que en la configuración del sistema tienen los recursos que los individuos poseen diferenciadamente (el más perspicuo de ellos, desde luego, es el

${ }^{65}$ Para los detalles del argumento, véase Atria, Mercado y Ciudadanía en la Educación. 
dinero, pero es importante notar que no es el único: poder, influencia, "capital cultural", etc. son recursos también distribuidos desigualmente). Habiendo hecho esto, es posible preservar la libertad y la igualdad: ya no es necesario recurrir a órdenes creados y sus mandatos concretos que tratan al individuo como instrumento, basta dejar que en esas condiciones cada uno persiga sus propias finalidades.

\section{CODA}

Es común hoy oír que lo que queda de diferencia entre derecha e izquierda es que la primera celebra el mercado y la segunda lo rechaza o al menos lo acepta a regañadientes. Por extensión, la idea de órdenes espontáneos, que se asocia primariamente con autores como Hayek o Adam Smith, es habitualmente recibida como una idea de derecha, al menos en el sentido de neoliberal. Esto nos deja enfrentados a la disyuntiva identificada al principio: o arriesgar la libertad por la vía de abandonar los órdenes espontáneos o (más probablemente, hoy por hoy) abandonar la idea de igualdad como ideal político para preservar la libertad y lo que la hace posible, los órdenes espontáneos. Ésta es una falsa disyuntiva. La cuestión, en realidad, es cómo pueden modificarse las condiciones en las que cada individuo persigue sus fines de modo que al hacerlo su acción, sumada a la de los demás que hacen lo mismo, forme un orden que tienda a la igualdad. No he pretendido, desde luego, responder cabalmente a esta pregunta, sino sólo plantearla: éste es el sentido en el que este artículo puede ser visto como programático. La realización de ese programa es lo que según Cohen nos falta, y que ahora podríamos llamar "microeconomía de la igualdad" (o, en rigor, "microeconomía de la igual libertad"). Tampoco he ofrecido un argumento que en general muestra que esa microeconomía es posible, pero espero haber dado razones para transformar las objeciones hayekianas en razones para estar optimistas al respecto. Si el argumento mencionado en la sección anterior (y desarrollado latamente en Mercado y Ciudadanía en la Educación) es correcto, tenemos una razón más para el optimismo: el hecho de que en una esfera de la ciudadanía sea posible encontrar micro-fundaciones para la igualdad nos da esperanzas de que en otros también lo será. Por ahora el argumento no prueba nada más, pero tampoco nada menos. 


\section{REFERENCIAS}

Atria, F. “La Relevancia del Derecho Civil”. Revista de Estudios de la Justicia 8 (2006), pp. 219-226.

- Mercado y Ciudadanía en la Educación. Santiago: Flandes Indiano, 2007.

"Sobre la Soberanía y lo Político". Revista de Derecho y Humanidades 12 (2007).

“La Verdad y lo Político (i): La Verdad y su Dimensión Constitutiva". Persona y Sociedad 23 (2009), pp. 21-50.

"La Verdad y lo Político (ii): Democracia y Ley Natural", en Persona y Sociedad 23 (2009), pp. 35-64.

“¿Qué Educación es ‘Pública'?”. En C. Bellei, D. Contreras y J. P. Valenzuela (eds), Ecos de la Revolución Pingüina. Santiago: UNICEF, 2010, pp. 153-181.

Atria, F. y C. Michelon. "Una Crítica al Principio de la Diferencia". En A. Squella (ed.), El Pensamiento Filosófico y Político de John Rawls. Valparaíso: EDEVAL, 2007.

Bentham, J. Fragmento sobre el Gobierno. Madrid: Aguilar, 1985.

Berlin, I.: "Dos Conceptos de Libertad". En I. Berlin, Libertad y Necesidad en la Historia. Madrid: Revista de Occidente, 1958, pp. 133-182.

Cohen, G. A. "Libertad y Dinero". Estudios Públicos 80 (2000), pp. 51-75.

"Por Qué No el Socialismo". En R. Gargarella y F. Ovejeros (eds.), Razones para el Socialismo. Barcelona: Paidos, 2002, pp. 63-85.

Darwin, C. The Origin of Species. London: Collector's Library, 2004 [ed. orig. 1859].

Eagleton, T. After Theory. London: Penguin, 2004.

Epstein, R. "Hayekian Socialism". Maryland Law Review 58 (1999), pp. 271-299.

Fischer, Á. La Mejor Idea Jamás Pensada. Santiago: Ediciones B, 2009.

Gaita, R. The Philosopher's Dog. London: Routledge, 2003.

Hamilton, A., J. Madison y J. Jay. The Federalist Papers. New York, NY: Oxford University Press, 2008 [ed. orig. 1788].

Hayek, F. "The Use of Knowledge in Society". En F. Hayek, Individualism and Economic Order. Chicago, Il: University of Chicago Press, 1945, pp. 77-91.

-Economics and Knowledge". En F. Hayek, Individualism and Economic Order. Chicago, Il: Chicago University Press, 1948 [ed. orig. 1937], pp. 33-56.

Individualism and Economic Order. Chicago, Il: Chicago University Press, 1948.

Rules and Order. Chicago, IL: University of Chicago Press, 1978.

Hobbes, T. Leviathan. Oxford: Oxford University Press, 1965 [ed. orig. 1651].

MacCormick, N. Institutions of Law. Oxford: Oxford University Press, 2007.

MacIntyre, A. After Virtue. A Study in Moral Theory. London: Duckworth, 1985.

Marshall, T. Citizenship and Social Class. London: Pluto, 1992 [ed. orig. 1950].

Rawls, J. A Theory of Justice. Cambridge, MA: Harvard University Press, 1971.

Rothstein, B. "El Fracaso de los Socialistas Europeos". La Nación, Santiago, 28 de junio 2009.

Silva, R. (ed.). Ideas y Confesiones de Portales. Santiago: Editorial del Pacífico, 1954. 
Smith, A. The Theory of Moral Sentiments. Indianapolis: Liberty Fund, 1984 [ed. orig. 1759].

Wright, E. O. "Compass Points: Towards a Socialist Alternative". New Left Review 41 (2006), pp. 93.124. 